Review

\title{
Energy Scenarios towards achieving SDG7 and the interlinkages with other Sustainable Development Goals: A Systematic
} Review

\author{
Fatma S. Hafez ${ }^{1 *}$, Da'u Abba Umar ${ }^{2}$, Y.H. Taufiq-Yap ${ }^{3}$, Saad Mekhilef ${ }^{4 *}$ \\ ${ }^{1}$ Power Electronics and Renewable Energy Research Laboratory (PEARL), Department of Electrical Engineering, Uni- \\ versity of Malaya, Kuala Lumpur 50603, Malaysia. \\ ${ }^{2}$ A Department of Environmental Sciences, Faculty of Science, Federal University Dutse, Dutse, Nigeria. \\ ${ }^{3}$ Catalysis Science and Technology Research Centre (PutraCat), Faculty of Science, University Putra Malaysia, 43400 \\ UPM Serdang, Selangor, Malaysia. \\ ${ }^{4}$ Department of Electrical Engineering, Faculty of Engineering, University of Malaya, 50603 Kuala Lumpur, Malaysia. \\ *correspondence: saad@um.edu.my; fatmaalzahraa.samihafez@gmail.com
}

\begin{abstract}
Accessing energy in the world is crucial nowadays. Energy is an essential factor to achieve other SDGs including SDG7. However, the determination and evaluation of the relationship between different energy scenarios to achieve SDG 7 and other SDGs have not done yet. This paper seeks to fill this gap by investigating how energy seniors can contribute to achieving SDG 7 and other SDGs. Web of Science, ScienceDirect and Scopus databases were utilized for conduction a systematic review. A total finial 25 from 249 papers were filtered from 2015 to December 2020 via inclusion and exclusion criteria. This review involves six seniors of energy which primary linked to achieving the SDG 7 and other SDGs: modern energy 20\% ( $n=5 / 25)$, energy access $16 \%(n=4 / 20)$, energy efficiency $8 \%(n=2 / 16)$, renewable energy $28 \%(n=7 / 14)$, energy services $8 \%(n=2 / 7)$, and miscellaneous energy $20 \%(n=5 / 5)$. This systematic review explores the opportunities, constraints and limitations, recommendations, and new directions. The results show that different energy scenarios contribute to achieving mainly (SDG7) and other SDGs. The outcomes from this systematic review provide a sense of direction for future researchers for future studies in this domain.
\end{abstract}

Keywords: Energy; Sustainable Development Goal 7; Sustainable Development Goals; Paris Agreement; 2030 agenda

\section{Introduction}

For 17 Sustainable Development Goals (UN-SDGs), the United Nations in 2015 endorsed the 2030 global agenda to cover multiple challenges including ending the poverty and hunger, eliminating inequality, overcome the climate change, access to clean energy, equality in gender, better education quality, clean water and sanitation [1-3]. One of the UN-SD goals are accessing "sustainable, affordable, modern, and reliable energy for every single one in this world" SDG 7, which has a lot of synergies and is in line with the rest of Sustainable Development Goals[4,5]. Sustainable development goal 7 has three main goals as follows: Firstly, universal energy access by modern energy or electricity which realizes 
the role of clean cooking for addressing and ensuring the sustainable energy services and ending the energy poverty for humankinds[6,7].

List of abbreviations.

\begin{tabular}{|c|c|c|c|}
\hline $3 C$ & Comfort, Cleanliness, and Convenience & Q1 & Q1 is occupied by the top $25 \%$ of journals \\
\hline CCSDI & Comprehensive Contribution to Sustainable Development Index & Q2 & Q2 is occupied between $25 \%-50 \%$ of journals \\
\hline $\mathrm{CO} 2$ & Carbon dioxide & Q3 & Q3 is occupied by journals in the 50 to $75 \%$ group \\
\hline COPRAS & Complex proportional assessment & Q4 & Q4 is occupied by journals in the 75 to $100 \%$ group \\
\hline DRE & Decentralised renewable energy & RE & Renewable energy \\
\hline EA & Energy and Atmosphere & RES & Renewable Energy Sources \\
\hline EU & European Union & SDG1-17 & Sustainable Development Goal 1-17 \\
\hline FNRB & Fraction of Non-Renewable Biomass & SDGs- IAE & Sustainable Development Goals impact assessment \\
\hline GB & Green Building & & framework for energy projects \\
\hline GHG & Greenhouse Gas & SJR & Scientific Journal Rankings \\
\hline HAP & Household Air Pollution & SLR & Systematic Literature Review \\
\hline HFL & Hesitant Fuzzy Linguistic & SRH & Slum Rehabilitation Housing \\
\hline ICS & Improved Biomass Cookstoves & SWAP- & The Soil-Water-Atmosphere-Plant (SWAP) model \\
\hline JCR & Journal Citation Reports & model & \\
\hline LCA & Life Cycle Analysis & UK & United Kingdom \\
\hline LED & Light-Emitting Diode & UN-SD & United Nations -Sustainable Development \\
\hline LEED & Leadership in Energy and Environmental Design & UN-SDGs & United Nations Sustainable Development Goals \\
\hline LEED $(B D+C$ New & Leadership in Energy and Environmental Design (Building Design and Construc- & USA & United Stated of America \\
\hline Construction) & tion) & WDI & World Development Indicators \\
\hline MCDM & Multi Criteria Decision Making & & \\
\hline PRISMA & Preferred Reporting Items for Systematic Reviews and Meta-Analyses & & \\
\hline PV & Photovoltaic & & \\
\hline
\end{tabular}

Access to modern energy such as cleaner cooking solutions is key factors to fulfil other sustainable development goals and their challenges and issues such as ending poverty in SDG1, "Ensuring healthy lives and promoting well-being for every single one in this world" in SDG3, equality education in SDG4, "achieving gender equality and empowering all women and girls" sustainable development goal 5, "protect terrestrial ecosystems, combat desertification sustainably manage forests" in SDG15, combatting the climate change in sustainable development goal 13 and other SDGs $[5,6,8]$. Secondly, increasing the share of Renewable Energy in the world, which has a strong relationship with some of the SDGs. For example: among the policymakers, the Renewable Energy Sources are recognised and considered as one of the potential solutions for electricity generation, sustainable growth, eliminate climate change with carbon emission reduction and energy security[9]. Countries can achieve the goal 7 in 2030 by growing the share of their Renewable Energy Sources in the global energy mix for maintaining their social and economic development with environment protection[10]. Moreover, in the industry and energy production, the aim of the renewable resource from land and sea such as bio-economy strategy is to substitute the fossil carbon with biomass to preserve the ecosystem, strength the relationship between economy, society and the environment[11]. Thirdly, an improved energy efficiency such as assessing the energy efficiency in the GB for achieving sustainable development goals target by adopting and implementing "Leadership in Energy and Environmental Design" (LEED) for mitigating the climate change and energy crisis[1,2]. Thus, Energy is a vital key factor for achieving goal 7 and for targeting other SDGs.

1.3 billion people in the world are living without accessing electricity because of their state of poverty and most of them are living in rural areas. A quarter of the population are also lacking in accessing clean cooking solutions and they depend on using the traditional ways because of the increase in population and lacking electricity infrastructure[5]. For example, about $60 \%$ Mozambican population are using kerosene for lighting and firewood 
for cooking and heating because they are living in the rural area and cannot access electricity[4]. More than 600,000 people die because of air pollution caused by using firewood and charcoal for cooking[12]. The development of a countries is cannot be sustain without energy supply, thus globally one person out of five cannot have access to electricity [10]. Moreover, the search or and cooking with firewood instead of using stoves and biomass effects the time of especially rural women and that directly negates the care and attention supposed to allotted to their children 'educations, health, and income generation, as well as preventing their girls to attend even the basic schools[5]. Besides, the emissions from using solid fuels are major sources of indoor air pollution results in many deaths per year as the same effected one by household air pollution(HAP)[6]. Thus, it is difficult for achieving the goal of health in SDG3, until we shift from solid to clean fuels. By income growth in SDG8 and majority who use solid fuels may live under the poverty in sustainable development goal 1 because they cannot shift to the modern one. At the same time, modern energy is not yet to target SDG $7[7,13]$. Across the MENA region, the heat sector and electricity are the highest and main source of $\mathrm{CO} 2$ emissions with about $71 \%$ and $65 \%$ demands from fossil fuels which, have a contributed significantly to the climate change crisis and the prices of electricity across many countries are high, and generally, the tax of energy is also high[14]. Additionally, there is no increase in renewable energy share and there is the declination in energy intensity annual rate which measuring the energy efficiency to be $2.4 \%$, which cannot reach $2.6 \%$ of the target by 2030 [7]. However, even renewables resources have many benefits in the energy system and certain challenges such as negative prices from the generated electricity from wind and solar which affect SDG 7, 8,12, and 13 [9]. Lacking regard of the rules, local justice recognitions, and relations affect negatively on the achievement of goal 7[5]. Lack of studies discussing the relationship and impacts between biofuels as renewable energy and food security in SDG2, energy in SDG7, and other SDGs has also contributed greatly[15].

Therefore, an energy such as electricity is an essential ultimate enabler of economic development that can end poverty and support sustainable industrialisation and urbanization [12]. Accessing electricity can provide desirable services such as education for children, poverty reduction, reduced health problems, socio-economic development, and empowerment for women and girls, improve the environmental consequences connect with soil nutrient loss and deforestation[5,8]. For supporting cleaner affordable and modern energy for cooking, two strategies are essential for example making available the clean energy such as Improved biomass cookstoves (ICS) models-gasifier stoves and making the clean energy available means making the gas and electricity accessible to everyone. The access to modern energy can benefits the environmental, health, and economic cost[6]. The justice distribution to the energy system can increase welfare by improving the capabilities of individuals to maximum use and enhance their well-being[16]. Using energy from renewable sources such as biofuel becomes crucial for reducing the dependence on fossil fuels[15]. One of the renewable solutions is using the Off-grid systems (small hydropower plants) which can give positive developmental, environmental, social, health, quality of life, and performance and also give cost-efficient power supply[4]. In the electricity infrastructure' future, the Off-grid houses are considered as an important element. Using leadacid batteries and solar PV also is considering as essential elements in renewable energy sources [17].

With this significant background and despite the governments, universities, and institutions of researchers have conducted various studies in types of energy scenario for achieving the SDG7 and their interlink with other SDGs in developing and developed countries but still no systematic review has been established yet that might have facilitated this field of research. Therefore, this systemic approach was conducted for better understanding and providing valuable insights into this domain and establishing a platform for additional studies by studying the constraints, opportunities, recommendations, limitations, and new directions between energy scenario towards sustainable development goal 7 and interlinking with other SDGs. This research focuses on the main constraints, which 
limit the previous academics from searching and examine this area. Besides, exploring the opportunities from selected papers for encouraging the authors to investigate and explore this topic with deep analysis. Moreover, previous selected reviews and articles are provided with recommendations for policymakers and stakeholders as guidelines that should be followed for more development. New directions for giving the future researchers the next path to overcome the remaining constraints which have not yet been solved.

This paper aimed was to implement a shallow systematic review and mapping into a coherent taxonomy for determining the types of energy such as modern energy (cooking solution), accessing energy such as electricity, increase sharing the renewable energy, and improve the energy efficiency for strengthening the evidence to raise the awareness and to increase the political wills to solve the existing challenges of energy. Therefore, this systematic review develops based on examination and analyses of energy scenario to achieve the targets of SDG 7 and interlinks same with other SDGs by addressing the co-benefits for ending poverty in (SDG1), food security in sustainable development goal 2, health in goal 3, education in (SDG4), gender in (goal 5), water in (sustainable development goal 6), energy in (SDG7), economic growth in (SDG8), building resilient, industrial, innovation in (SDG9), equality in (SDG10), cities in (SDG11), consumption in (SDG12), climate change in (sustainable development goal13). The findings and results are utilized for discussing the implications[6, 7, 9].

This research is formulated as follows: this part is discussing the background of energy scenario with some existing constraints and importance of the energy to SDGs and what is the main aim of this review. Part two utilized the system protocol for how energy scenario can achieve the sustainable development goal 7 and interlink them with other SDGs through putting research questions, search strategy, search string, inclusion and exclusion criteria, data synthesis. Part three is mapped this study based on the previous studies from selected reviews and articles, which is charted and arranged into a coherent taxonomy. Besides, part four presented the opportunities, constraints, recommendations, limitation, and new directions for future research, which were performed by previous researchers from the previous studies on energy scenario to achieve SDG7 and interlink towards other sustainable development goals from (2015 - 31December 2020). Part five presents the conclusions.

\subsection{Materials and Methods}

Systematic Review Protocol

The Systematic Literature Reviews are carried out in different fields by published studies in different areas, which is the way of examining and analysing specific areas objectively[18]. The main reason for using the SLRs is to systematically explore, appraise, and conclude from all relevant published articles associated with specific questions for a certain topic to give complete information for future research. To carry out the Systematic Literature Review (SLR), the protocol should be implemented[18]. The main steps of conducting the Systematic Literature Review is reviewing the PRISMA protocol, defining the search strategies to identify the relevant literature, documenting the search strategies, involving the inclusion and exclusion criteria for determining the primary studies should be covered in the research, using the quality criteria to evaluate the primary studies[18]. The following sub-sections are briefed describe the phases of developing the protocol to conduct the Systematic Literature Review (SLR)as showing the Figure 2

2.1. Questions of this research

The research questions for conducting this systematic review are:

RQ 1. What research has been done on the impacts of the energy scenarios towards SDG 7 and their interlink with other SDGs from January 2015 till November 2020?

RQ 2. How we categorize the energy scenarios to achieve sustainable development goal 7 and interlink them with other SDGs from January 2015 till November 2020? 
RQ 3. What are the methodical aspects of this review?

RQ 4. What are the opportunities, constraints, limitations, recommendations, and a new? directions have been found in the previous studies in this domain?

\subsection{Search strategy}

The search process is well formulated by executing available reliable resources for identifying all the existing studies associated with this topic by meeting the defined search criteria. The systematic literature review is a formal search process for conducting a review of all the materials to each database. For maintaining the standard of systematic literature review (SLR), use reliable articles from well-reputed databases. Three databases were selected to choose the target articles for this SRL, which are (a. Web of Science, b. ScienceDirect, and c. Scopus). These databases have been selected based on their academic reliability in different journal articles from medical, sciences, social, arts, and humanities disciplines. The systematic literature review is conducted based on five keywords related to the environmental sciences, which were searched at 31December 2020 in these databases shown in Figure 1.

\subsection{Search string}

Firstly, the authors have decided to choose the appropriate databases and keywords related to the present research. The keywords defined which include ("energy") AND ("SDG 7" OR "Sustainable Development Goal 7" OR "Goal 7") AND ("SDGs" OR "Sustainable Development Goals" OR "Sustainable Development Goal" OR "SDG"). The Articles and reviews received from the reliable databases which are based on the keywords used as a channel for developing and validating the key search terms. Different word combinations and various phrases have adopted for defining three different groups: The "AND" operator was used between the three different groups, and "OR" operator was utilised inside each group for clustering the words, which have a similar meaning.

The first group related to energy followed by the second group, which focuses on the term goal 7. The last group of this search focused on the other SDGs as shown in Figure 2. The authors implemented few options during adopting the protocol to exclude reports, books, and chapters and include journal articles reviews only which are relevant to our main topic. The final list of reviews and articles are obtained as shown in Table.1 after filtration by title, abstract and the full content is given in Figure 2. 
Web of Science InCites Joumal Citation Reports Essential Science Indicators EndNote Publons Kopernio Master Jourbigntilat $\boldsymbol{\nabla}$ Help $\boldsymbol{\nabla}$ English $\boldsymbol{\nabla}$

\section{Web of Science}

1 Clarivate Analytics

$$
\text { Search }
$$

\begin{tabular}{|l|l|}
\hline $\begin{array}{l}\text { Results: } 98 \\
\text { (from Web of Science ce }\end{array}$ \\
\hline
\end{tabular}

You searched for: (TS=("energy") A ND TS=("SDG 7" OR "Sustainable Dev elopment Goal 7" OR "Goal 7") ANDT $S=$ ("SDGs" OR "Sustainable Develod
Tools - Searches and alerts - Search History Marked List

\section{ScienceDirect}

Find articles with these terms

Year: 2015-2020 X

Title, abstract, keywords: ("energy") AND("SDG 7" OR "Sustainable Development Goal 7" OR "Goal 7... X

$\vee$ Advanced search
48 results
¿ Download selected articles
¿ Export
relevance | date
य setseartratert
Research article Open access

SDGs in action: A novel framework for assessing energy projects against the

Refine by: sustainable development goals

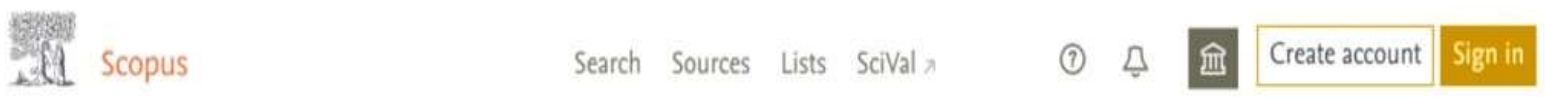

\section{5 document results}

TITLE-ABS-KEY ( "energy") AND ("SDG 7" OR "Sustainable Development Goal7" OR "Goal 7") AND ("SDGs" OR "Sustainable Development Goals" OR "SDG" OR "Sustainable Development Goal")) AND DOCTYPE (ar OR re) AND PUBYEAR > 2014 AND PUBYEAR < 2021 AND (LIMTT-TO (LANGUAGE, "English"))

2 Edit 1 Save $\Delta$ Setalert

Search within results... Documents Secondary documents Patents

Figure 1. Initial results obtained from the searching process has been taken on 31 December 2021. 


\section{Research questions}

("energy") AND ("SDG 7" OR "Sustainable Development Goal 7" OR "Goal 7") AND ("SDGs" OR "Sustainable Development Goals" OR "SDG" OR "Sustainable Development Goal")

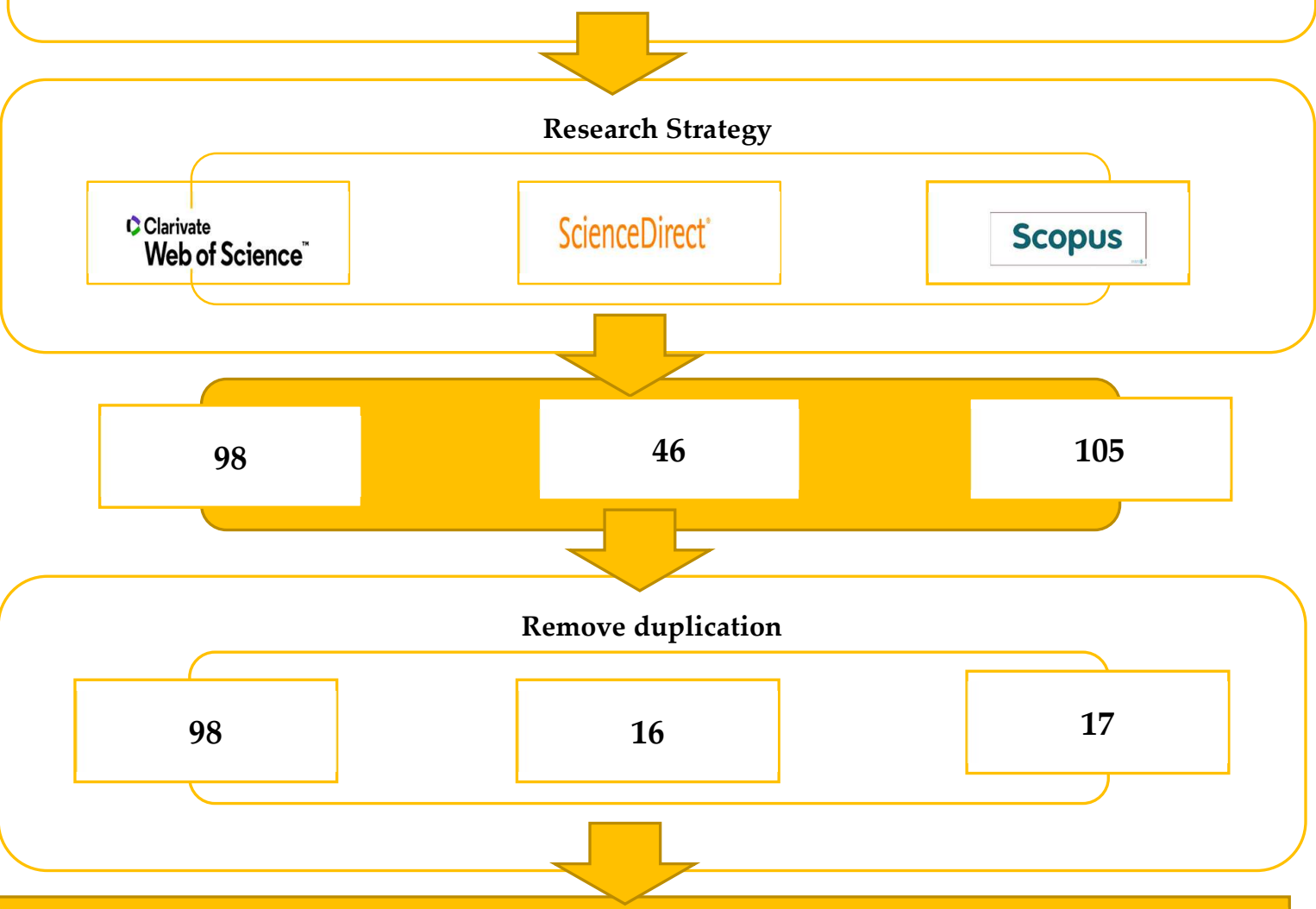

Article screen (Inclusion and exclusion criteria)
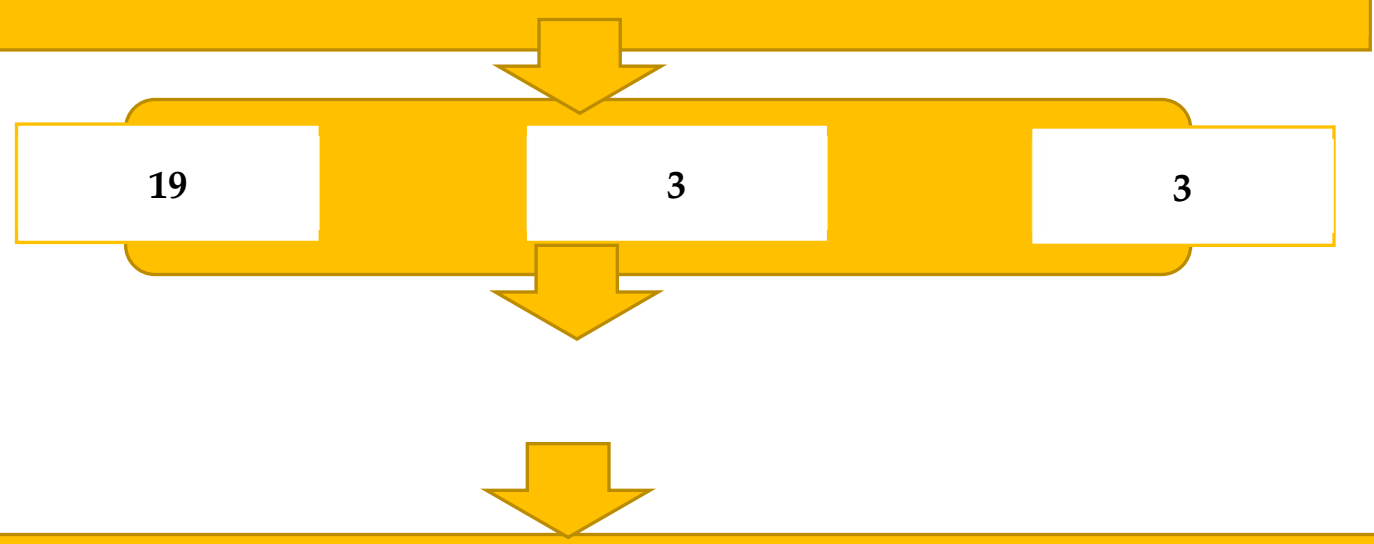

Data Synthesis

Data Extraction

Figure 2. The protocol of conducting SRL. 
Table 1. Details of the selected papers.

\begin{tabular}{|c|c|c|c|}
\hline No & Citation & Title & Year \\
\hline \multicolumn{4}{|c|}{ Review } \\
\hline 1 & 0 & $\begin{array}{l}\text { Biofuels and their connections with the sustainable development goals: a } \\
\text { bibliometric and systematic review. }\end{array}$ & 2020 \\
\hline 2 & 0 & $\begin{array}{l}\text { Challenges of achieving Sustainable Development Goal } 7 \text { from the } \\
\text { perspectives of access to modern cooking energy in developing countries. }\end{array}$ & 2020 \\
\hline 3 & 4 & $\begin{array}{l}\text { The Role of Off-Grid Houses in the Energy Transition with a Case Study in } \\
\text { the Netherlands. }\end{array}$ & 2019 \\
\hline 4 & 30 & $\begin{array}{l}\text { Towards the achievement of SDG } 7 \text { in sub-Saharan Africa: Creating } \\
\text { synergies between Power Africa, Sustainable Energy for All and climate } \\
\text { finance in-order to achieve universal energy access before } 2030 \text {. }\end{array}$ & 2018 \\
\hline \multicolumn{4}{|c|}{ 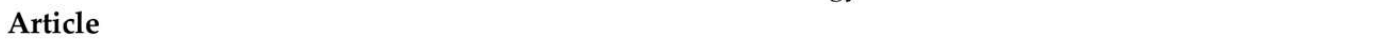 } \\
\hline 1 & 2 & $\begin{array}{l}\text { A comprehensive analysis of cooking solutions co-benefits at household } \\
\text { level: healthy lives and well-being, gender and climate change. }\end{array}$ & 2020 \\
\hline 2 & 4 & $\begin{array}{l}\text { A new index for assessing the contribution of energy efficiency in LEED } \\
2009 \text { certified green buildings to achieving UN sustainable development } \\
\text { goals in Jordan. }\end{array}$ & 2020 \\
\hline 3 & 9 & $\begin{array}{l}\text { SDGs in action: A novel framework for assessing energy projects against } \\
\text { the sustainable development goals. }\end{array}$ & 2020 \\
\hline 4 & 2 & $\begin{array}{l}\text { An assessment of energy policy impacts on achieving Sustainable } \\
\text { Development Goal } 7 \text { in Indonesia. }\end{array}$ & 2020 \\
\hline 5 & 0 & $\begin{array}{l}\text { Blue Economy: compatibility between the increasing Offshore wind } \\
\text { technology and the achievement of the SDG. }\end{array}$ & 2020 \\
\hline 6 & 0 & $\begin{array}{l}\text { Can energy conservation and substitution mitigate } \mathrm{CO} 2 \text { emissions in } \\
\text { electricity generation? Evidence from Middle East and North Africa. }\end{array}$ & 2020 \\
\hline 7 & 8 & $\begin{array}{l}\text { Developing an indicator set for measuring sustainable development in } \\
\text { India. }\end{array}$ & 2020 \\
\hline 8 & 12 & Renewable electricity and sustainable development goals in the EU. & 2020 \\
\hline 9 & 4 & $\begin{array}{l}\text { Energy Justice in Slum Rehabilitation Housing: An Empirical Exploration } \\
\text { of Built Environment Effects on Socio-Cultural Energy Demand. }\end{array}$ & 2020 \\
\hline 10 & 2 & $\begin{array}{l}\text { Energy-Climate-Economy-Population Nexus: An Empirical Analysis in } \\
\text { Kenya, Senegal, and Eswatini. }\end{array}$ & 2020 \\
\hline 11 & 5 & $\begin{array}{l}\text { Evidence of gender inequality in energy use from a mixed-methods study } \\
\text { in India. }\end{array}$ & 2020 \\
\hline 12 & 15 & $\begin{array}{l}\text { Friends or foes? A compatibility assessment of bio economy- } \\
\text { related Sustainable Development Goals for European policy coherence. }\end{array}$ & 2020 \\
\hline 13 & 0 & Global Trends Impacting Gender Equality in Energy Access. & 2020 \\
\hline 14 & 3 & $\begin{array}{l}\text { Integrated spatial and energy planning: a means to reach sustainable } \\
\text { development goals. }\end{array}$ & 2020 \\
\hline 15 & 7 & $\begin{array}{l}\text { Mini-Grid Hydropower for Rural Electrification in Mozambique: Meeting } \\
\text { Local Needs with Supply in a Nexus Approach. }\end{array}$ & 2019 \\
\hline 16 & 2 & $\begin{array}{l}\text { Empowered by electricity? The political economy of gender and energy in } \\
\text { rural Naryn. }\end{array}$ & 2019 \\
\hline 17 & 23 & $\begin{array}{l}\text { Two Birds, One Stone - Reframing Cooking Energy Policies in Africa and } \\
\text { Asia. }\end{array}$ & 2019 \\
\hline 18 & 36 & $\begin{array}{l}\text { A novel renewable energy selection model for united nations' sustainable } \\
\text { development goals. }\end{array}$ & 2018 \\
\hline 19 & 27 & $\begin{array}{l}\text { Assessing the contribution of water and energy efficiency in green } \\
\text { buildings to achieve United Nations Sustainable Development Goals in } \\
\text { Jordan. }\end{array}$ & 2018 \\
\hline 20 & 4 & $\begin{array}{l}\text { Energy poverty in healthcare facilities: a "silent barrier" to improved } \\
\text { healthcare in sub-Saharan Africa. }\end{array}$ & 2018 \\
\hline 21 & 15 & $\begin{array}{l}\text { Supporting local farming communities and crop production resilience to } \\
\text { climate change through giant reed (Arundo donax L.) cultivation: An } \\
\text { Italian case study. }\end{array}$ & 2017 \\
\hline
\end{tabular}




\subsection{Inclusion and Exclusion criteria}

During the search process, it was found many journal publications such as articles, books, conferences, workshops, and other materials. The pre-defined keywords were manually searched using the three databases which have mentioned in Figure 1. The bibliographic information was managed by using the Mendeley reference software, which includes the author name, the title of the paper, the journal's name, and the year of publication [18]. The authors have decided to include, or exclude the papers based on the inclusion and exclusion criteria as shown in Table 2. and Table 3. by going through different stages such as reading the title, scanning the abstract, reading the full text of the paper, and then the result, several irrelevant documents were excluded. This process selected the most relevant articles and reviews assessed depend on the given inclusion and exclusion criteria [18]. The final list of the selected papers with their title, citations, year of publication is given in Table 1. There is a rise in the publications in this emerging topic as shown in Table 4., as result, there is gaining significance in this area in the coming years.

Table 2. Inclusion criteria.

1-The relevant paper from year January 2015 to 6 December 2020.

2-The article was written in the English language.

3-The relevant paper is answered the research questions.

4-The relevant paper is found in the main selected database as in Figure 2.

5- The focus on energy Scenario towards achieving SDG 7 and interlink with other SDGs.

Table 3. Exclusion criteria.

1-The paper out of the range before the year 2015.

2- The paper is not in the English language.

3-The paper is in another type of document than article or review.

4-The relevant paper is not associated with the research questions.

Table 4. Year division of the selected paper.

\begin{tabular}{lllll}
\hline Type of paper & 2017 & 2018 & 2019 & 2020 \\
Review & 0 & 1 & 1 & 2 \\
Article & 1 & 3 & 3 & 14 \\
\hline
\end{tabular}

\subsection{Data synthesis}

The data synthesis process was done by three authors and as a result, the data extraction was presented in Figure 2. However, Figure two has shown the protocol of data synthesis through the keyword terms, search process, inclusion and exclusion criteria, and the filtering process based on achieving the research questions. There was a separate folder maintained for each database and a total of 249 articles and reviews were found. In the beginning, each folder of each database was checked manually, and all the articles and reviews were numbered by their titles. Secondly, the duplications were deleted by checking the title of each paper in the excel sheet file. These papers are obtained and then investigated manually by title and abstract to reach a total of 114 articles and 17 reviews. Finally, the results from the previous process were again filtered manually by reading and examine the full text, and as a result of the total of 21 articles and 4 reviews were selected. These 25 documents were done in the Mendeley reference manager library with their citation management. Then, the selected papers were used by defining the research questions and the query in the process of proposed the protocol of systematic literature review. 


\section{Analysis and Results}

In this part, the authors highlighted within 25 studies about energy scenario towards sustainable development goals from 2015 - December 2020, the findings of the systematic review findings are presented based on the four research questions.

\subsection{How we categorize the energy scenarios to achieve sustainable development goal 7 and inter-} link them with other SDGs from January 2015 till November 2020?

The first question aims to know how the energy scenario has been classified to achieve sustainable development goal 7 . The process initiated by searching first, and scanning second, and filtering third and final with the full-text reading of all papers in the databases. After completing the previous phases, all selected reviews, which gives an overall about the energy across many aspects and articles, which have deep analysis with discussion and results were classified the energy into six scenarios to Modern Energy, Energy Access, Energy Efficiency, Renewable Energy, Energy Services, and Miscellaneous Energies.

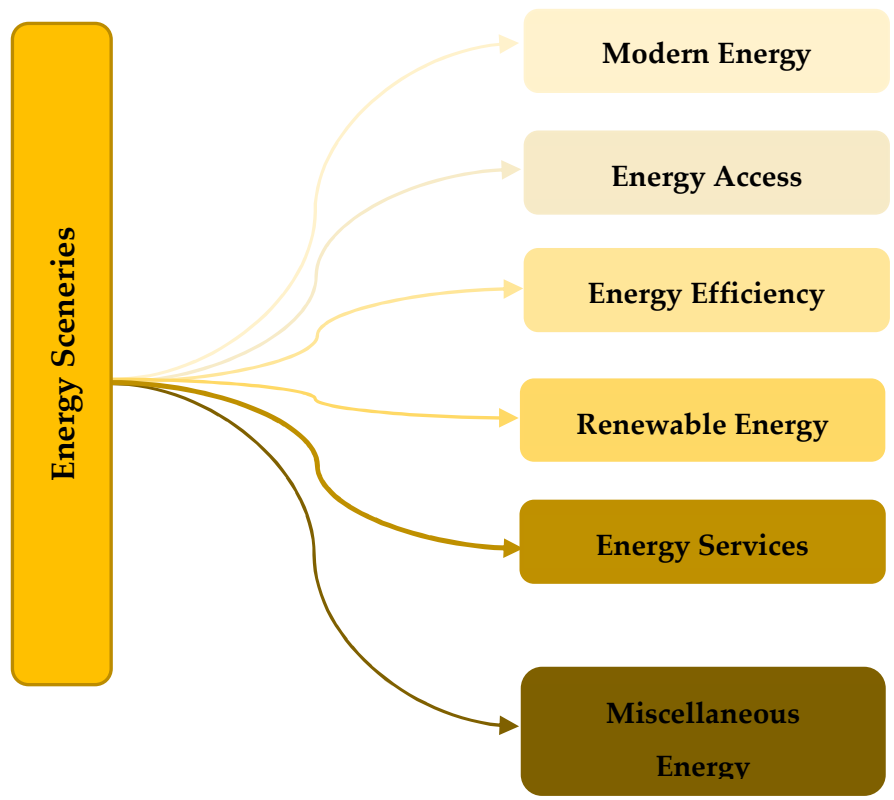

Figure 3. Classifications of the energv scenarios.

\subsubsection{Energy scenarios}

\subsubsection{Scenario 1: Modern Energy}

We found out of $(n=25)$ studies $(n=5)$ four articles and one review is related to modern energy scenario 1 towards achieving sustainable development goal 7 and connect with other SDGs. In developing countries, presenting the concerns to achieve SDG 7 in the context of accessing modern cooking energy [5]. Developing a framework by utilizing a comprehensive approach for analysing and comparing of various benefits of clean cooking solutions towards Health in (sustainable development goal 3), gender (sustainable development goal 5) and climate change (sustainable development goal 13) using costbenefit analysis[6]. In Indonesia, evaluating and examining the effectiveness of energy laws and regulations with their contribution to achieve the SDGs' energy targets[7]. Performing the analytic framework of feminist political economy approach for exploring the potential of access to electricity to empower the women[8]. In the Global South, designing new strategy, the modern energy cooking services for exploring different approaches for addressing the cooking energy concerns[13]. 


\subsubsection{Scenario 2: Energy Access}

We found out of $(n=25)$ studies $(n=4)$ three articles and one review is related to how to access energy to target SDG 7 and joining it with other Sustainable development goals. Analysing case studies, project reports, research articles and policy briefs for investigation the policies, innovations, and strategies, which could help in urging subSaharan Africa's progress to reach universal energy access before 2030 [12]. In sub-Saharan Africa, designing effective policies by documenting the change in accessing the modern energy for health facilities[19]. Using a mixed-methods study by assessing the household appliance used by gender in Gujarat $(n=31)$ and generalising this assessment to the other six states in India[3].Taking attention to the ways that drive and obstruct the equality of gender in access energy[20].

\subsubsection{Scenario 3: Energy Efficiency}

We found out of $(n=25)$ studies $(n=2)$ articles are related to energy efficiency scenario. In Jordan, proposing a new (CCSDI) tool for assessing the energy efficiency' contributions in LEED 2009 certification to green buildings to achieve United NationSDGs $[1,21]$.

\subsubsection{Scenario 4: Renewable Energy}

We found out of $(n=25)$ studies $(n=7)$ five articles and two reviews are related to the renewable energy scenario. Exploring the relation between biofuel and SDGs to show the main challenges, opportunities, and current developments[15]. Reviewing the development of increasing the electricity access by implementing off-grid houses within different scenarios by considering their existing challenges on the macro and micro level[17]. Offering a numerical model for sustainable development goals, which associates Analytic Hierarchy Process method with complex proportional assessment technique (COPRAS) depend on (HFL) the term set for identifying and determining the most appropriate renewable energy sources for reaching sustainable development goals targets [10]. Studying the life cycle analysis (LCA) procedure by applying data from (2000-2015) using ridge regression techniques and stochastic frontier trans log production for estimating energy intensity and energy efficiency to $\mathrm{CO} 2$ mitigate emissions[14]. Analysing the links between the European Union bio-economy strategy and the SDGs by assessing the main points of synergies and trade-offs that related to sustainable development goals targets[11]. Adopting of renewable electricity impacts on SDGs such as goal 7, goal 8, goal 9, goal 12 and goal 13 via electricity prices by analysing data sourced at the country level from the Eurostat database and the World Bank's (WDI)[9]. Performing the (SWAP) model for estimating the giant reed response under the climate change in the marginal areas and determining the water productivity index for giant reed with supported economic evaluation for determining expected farm incomes[22].

\subsubsection{Scenario 5: Energy Services}

The authors found out of $(n=25)$ studies $(n=2)$ articles are related to energy services scenario. Establishing a model between the comfort, cleanliness, and convenience-(3C) with socio-architectural elements by utilising Firth procedure's Binary Logistic Regression to distributive justice in poverty and to mitigate the rising in energy demand[16]. At a local level, suggesting a nexus approach using a mini-grid hydropower system to energy production in a small-scale factory to grind corn and other cereals for improving water, energy, and food security for 80-200 households [4].

\subsubsection{Scenario 6: Miscellaneous Energies}

Contributing to the offshore wind technology for achieving the sustainable development goal to make the energy bluer[2]. In India, proposing a technique to develop an indicator set for sustainable development measurement depends on the sustainable 
development goals by considering the country's needs and preferences [23]. Examining the relationship between energy consumption in goal 7, climate change in goal 13, economic growth and population in goal 8 by using machine learning technique (KRLS), Mean-Group, (DOLS) econometric methods, (FMOLS) regression, and estimation models such as (PMG)[24]. Integrating spatial and energy planning by using Austrian experiences results to reach energy transition based on energy strategies, for example, accessing modern energy, producing energy saving, increasing the renewable energy sources, and improving the energy efficiency to target SDG7 and to reach to SDGs [25]. For Energy Projects, developing the SDGs Impact Assessment Framework for assessing synergies and trade-offs of sustainable development goal targets [26].

\subsection{Methodological aspects}

This part discusses the methodological aspect of the selected articles and reviews with the relation of energy scenarios towards achieving SDG 7and other SDGs. Various questions are discussed to inform the future authors and researchers about this area with settings and features have been applied before.

3.2.1. What are the most active countries in this domain for boosting the energy scenario towards sustainable development goal 7 and interlink with SDGs?

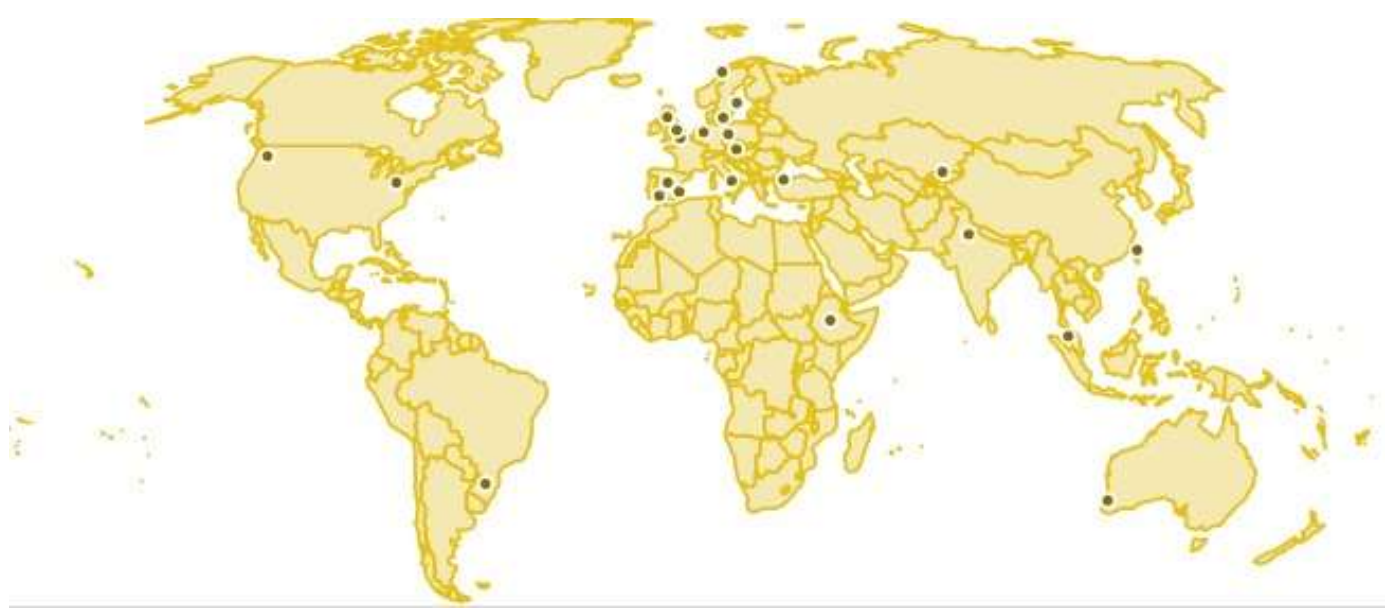

Figure 4. Distribution of countries in world map by study' implementation.

Energy scenarios in the context of SDGs were studied in different countries. Thus, this research has earned serious interest from researchers, policymakers, and governments, who may be adopting and applying these studies in social, medical, economic, humanities, political, environmental research and other purposes as well. These studies have been conducted on 18 countries as shown in Table 5 and Figure 4 . The countries that have 3 studies ( $n=2 / 18)$ Spain and the UK. Ethiopia, Malaysia, and Sweden come as second with two studies $(n=12 / 16)$. The last group with only one study involves countries $(n=13 / 13)$ such as Australia, Australia, Brazil, China, Germany, Ghana, India, Italy, Kyrgyzstan, Netherlands, Norway, Turkey, and the USA. 
Distribution of countries regarding their studies of implementation.

Table 5. Distribution of countries by study' implementation.

\begin{tabular}{|c|c|c|}
\hline Country & Type of Study & Reference \\
\hline Australia & Article & [7] \\
\hline Austria & Article & [25] \\
\hline Brazil & Review & [15] \\
\hline China & Article & {$[14]$} \\
\hline Ethiopia & Review & {$[5,19]$} \\
\hline Germany & Review & [12] \\
\hline Ghana & Article & [9] \\
\hline India & Article & [23] \\
\hline Italy & Article & [22] \\
\hline Kyrgyzstan & Article & [8] \\
\hline Malaysia & Articles & {$[1,21]$} \\
\hline Netherlands & Review & [17] \\
\hline Norway & Article & {$[24,8]$} \\
\hline Spain & Articles & {$[6,2,11]$} \\
\hline Sweden & Article & {$[4,26]$} \\
\hline Turkey & Article & [10] \\
\hline UK & Articles & {$[16,20,13]$} \\
\hline USA & Article & [3] \\
\hline
\end{tabular}

3.2.2. What are the active journals in the research domain in the context of energy scenario toward SDG 7 and their interlink with other Sustainable Development Goals?

In this section, it shows the classification of related studies with ISI journals, research domain, and to know the impact factor from journal citation report or scimago journal and country rank. This type of classification assistance the researchers to target journal related to energy scenario and their interlink with SDGs (Table 2). It shows that Sustainably with $[16,24]$, Science of the Total Environment[6, 22], and Energies [13,17] journals are considered the most active Journals among others in this field with 2 published articles and the remaining journals with only one study as shown in Table 6.

Table 6. Top active journals in the field with their impact factor from (2015-2020).

\begin{tabular}{|c|c|c|c|c|c|c|}
\hline No & Journal & Research domain/ Categories & JCR/SJR & IF & Quartile & Ref \\
\hline 1 & $\begin{array}{l}\text { Environment, Develop- } \\
\text { ment and Sustainability }\end{array}$ & $\begin{array}{l}\text { 1-Economics, Econometrics and Finance } \\
\text { Economics and Econometrics } \\
\text { 2-Environmental Science Management, } \\
\text { Monitoring, Policy and Law } \\
\text { 3-Social Sciences Geography, Planning and } \\
\text { Development. }\end{array}$ & SJR & .55 & Q2 & [15] \\
\hline 2 & $\begin{array}{l}\text { Frontiers in Energy Re- } \\
\text { search }\end{array}$ & $\begin{array}{l}\text { 1-Economics, Econometrics and Finance } \\
\text { Economics, and Econometrics. } \\
\text { 2-Energy Engineering and Power Technol- } \\
\text { ogy, Fuel Technology, Renewable Energy, } \\
\text { Sustainability and the Environment. }\end{array}$ & SJR & .64 & Q2 & {$[5]$} \\
\hline 3 & $\begin{array}{l}\text { Renewable and Sustainable } \\
\text { Energy Reviews }\end{array}$ & $\begin{array}{l}\text { 1-Green\& sustainable Science \&Technol- } \\
\text { ogy. } \\
\text { 2- Energy \& Fuels. }\end{array}$ & JCR & 12.110 & Q1 & [12] \\
\hline 4 & $\begin{array}{l}\text { Science of the Total Envi- } \\
\text { ronment }\end{array}$ & 1-Environmental Sciences. & JCR & 6.551 & Q1 & {$[6,22]$} \\
\hline
\end{tabular}




\begin{tabular}{|c|c|c|c|c|c|c|}
\hline 5 & $\begin{array}{l}\text { International Journal of } \\
\text { Green Energy }\end{array}$ & $\begin{array}{l}\text { 1-Thermodynamics. } \\
\text { 2-Green\& sustainable Science /Technology. } \\
\text { 3-Energy\&Fuels. }\end{array}$ & JCR & 1.388 & Q4 & {$[1]$} \\
\hline 6 & Energy & $\begin{array}{l}\text { 1-Thermodynamics. } \\
\text { 2-Energy\&Fuels. } \\
\text { 3- Engineering \& Chemical. }\end{array}$ & $\mathrm{JCR}$ & 6.082 & Q1 & {$[10]$} \\
\hline 7 & $\begin{array}{l}\text { Energy for Sustainable De- } \\
\text { velopment }\end{array}$ & $\begin{array}{l}\text { 1-Green\&sustainable Science /Technology. } \\
\text { 2- Energy \& Fuels. }\end{array}$ & JCR & 3.610 & Q3/Q2 & [7] \\
\hline 8 & Building and Environment & $\begin{array}{l}\text { 1-Construction \& building Technology. } \\
\text { 2-Engineering \&Environmental Science. } \\
\text { 3-Engineering \& Civil Science. }\end{array}$ & JCR & 4.971 & Q1 & {$[21]$} \\
\hline 9 & Journal of Coastal Research & $\begin{array}{l}\text { 1-Geography, Physical. } \\
\text { 2-Geosciences, Multidisciplinary. } \\
\text { 3-Geosciences, interdisciplinary. } \\
\text { 4-Marine\& Freshwater biology. }\end{array}$ & JCR & 0.793 & Q1 & {$[2]$} \\
\hline 10 & $\begin{array}{l}\text { Journal of Environmental } \\
\text { Management }\end{array}$ & 1-Environmental Sciences. & JCR & 5.647 & Q1 & {$[14]$} \\
\hline 11 & Natural Resources Forum & 1-Environmental Sciences. & $\mathrm{JCR}$ & 1.436 & Q4 & [23] \\
\hline 12 & $\begin{array}{l}\text { Gender, Technology and } \\
\text { Development }\end{array}$ & $\begin{array}{l}\text { Social Sciences Development } \\
\text { Gender Studies. }\end{array}$ & SJR & 0.61 & Q1 & {$[8]$} \\
\hline 13 & Sustainability & $\begin{array}{l}\text { 1-Green \& sustainable science /Technology. } \\
\text { 2-Environmental Sciences. }\end{array}$ & JCR & 2.576 & Q2 & {$[16,24]$} \\
\hline 14 & $\begin{array}{l}\text { Journal of Public Health } \\
\text { Policy }\end{array}$ & $\begin{array}{l}\text { 1-Health Care Sciences \& Services } \\
\text { 2-Public, Environmental \& Occupational } \\
\text { Health }\end{array}$ & $\mathrm{JCR}$ & 1.500 & Q4/Q3 & {$[19]$} \\
\hline 15 & Nature Sustainability & 1-Environmental Sciences & JCR & 12.080 & Q1 & [3] \\
\hline 16 & $\begin{array}{l}\text { Journal of Cleaner Produc- } \\
\text { tion }\end{array}$ & $\begin{array}{l}\text { 1-Green \& sustainable science /Technology } \\
\text { 2-Engineering \&Environmental Science } \\
\text { 3- Environmental Sciences }\end{array}$ & JCR & 7.246 & Q1 & {$[11]$} \\
\hline 17 & $\begin{array}{l}\text { IDS Bulletin-Institute of } \\
\text { Development Studies }\end{array}$ & $\begin{array}{l}\text { 1-Development studies } \\
\text { 2-Area studies } \\
\text { 3-Planing \&Development }\end{array}$ & $\mathrm{JCR}$ & 0.606 & Q3/Q4 & {$[20]$} \\
\hline 18 & $\begin{array}{l}\text { Evolutionary and Institu- } \\
\text { tional Economics Review }\end{array}$ & $\begin{array}{l}\text { 1- economic history, } \\
\text { 2-economic thought } \\
\text { 3-economic theory } \\
\text { 4- management science }\end{array}$ & - & - & - & [25] \\
\hline 19 & Water & 1-Water Resources & JCR & 2.544 & Q2 & {$[4]$} \\
\hline 20 & World Development & $\begin{array}{l}\text { 1-Economic } \\
\text { 2-Development studies }\end{array}$ & $\mathrm{JCR}$ & 3.869 & Q1 & [9] \\
\hline 21 & $\begin{array}{l}\text { Energy Research \& Social } \\
\text { Science }\end{array}$ & 1-Environmental studies & $\mathrm{JCR}$ & 4.771 & Q1 & {$[26]$} \\
\hline 22 & Energies & 1-Energy \& Fuels & $\mathrm{JCR}$ & 2.702 & Q3 & {$[13,17]$} \\
\hline
\end{tabular}

\subsubsection{What is the distribution of selected studies per years?}

The initial search is generated from the three databases 223 articles and 26 reviews. This step has three phases, which include duplicating, screening the title, keywords and abstract, the finial filtering by reading and examining the full text to determine whether the article or the review paper will be suitable or not in this SLR and categorized these papers, which have the same features and similarities in various folders. The first phase 
was the duplicating which excluded in the excel datasheet to reach 114 articles and 17 reviews. After the second and third phase, the articles and reviews have reached 21 and 4 respectively as shown in Table 1 . Several comments are taken throughout the three phases. Each review or article is analysed separately in the Microsoft word file with many attributes. All selected papers have gone through the same process and every reference for these papers was added to a separate column in the table of the Microsoft word file. The result shows in Figure 6 that there is one study only in 2017. Four studies in 2018 as well as in 2019. In 2020, the studies in this field have increased rapidly, which means the researchers have interest and intention to explore more in this area specially the impact of energy in achieving SDGs.

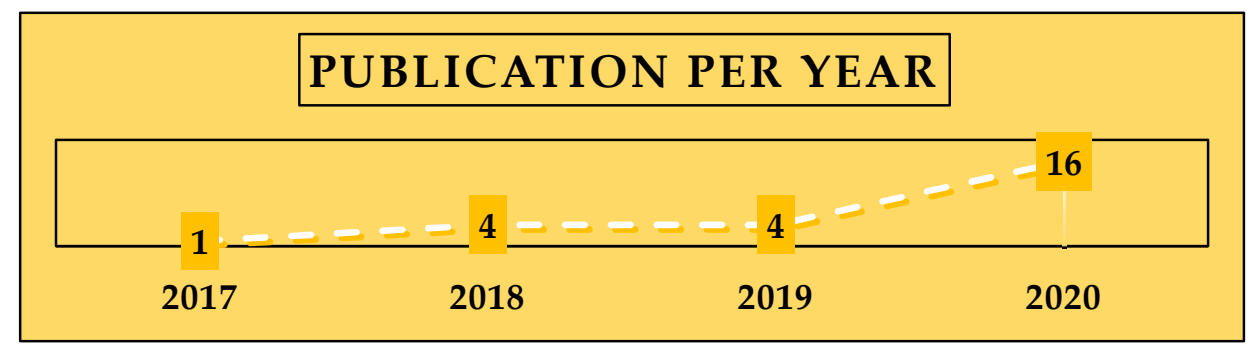

Fig 5. Distribution the related studies in this domain per year.

3.2.4. What is the relation between the energy scenarios toward achieving sustainable development goal 7 and other sustainable development goals?

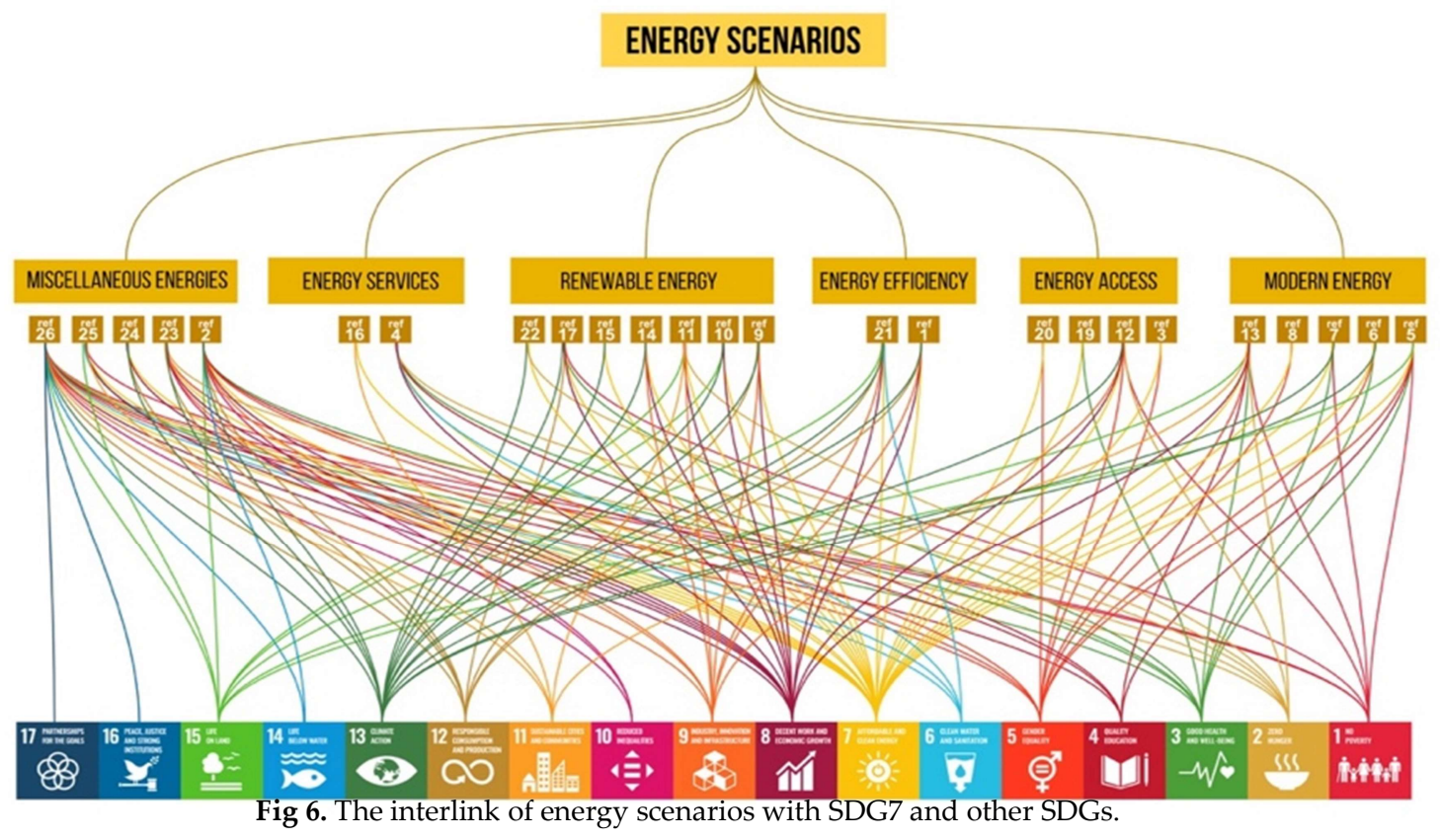


Table 7. The interlink of energy scenarios with SDG7 and SDGs.

\begin{tabular}{|c|c|c|}
\hline Ref & Energy scenarios & Interlink with other sustainable development goals \\
\hline \multicolumn{2}{|c|}{ Scenario 1: Modern Energy } & Synergies \&Trad-off \\
\hline [5] & Cooking energy access & $\begin{array}{l}\text { The SDG } 7 \text { has a lot of synergies with: } \\
\text { 1-Goal } 1 \text { to end poverty. } \\
\text { 2-Goal } 3 \text { for ensuring (healthy lives) and promoting (well-being). } \\
\text { 3-Goal } 4 \text { to ensure equitable quality education. } \\
\text { 4-Goal } 5 \text { for achieving (gender equality) and empowering (all women and girls). } \\
\text { 5-Goal } 15 \text { to protect sustainable ecosystems, manage forests, combat desertification, re- } \\
\text { verse land degradation, and halt biodiversity loss. }\end{array}$ \\
\hline [6] & Clean cooking solutions & $\begin{array}{l}\text { The co-benefits of clean cooking solutions such as: } \\
1 \text {-contributing to } 1 \% \text { Health in SDG } 3 \\
2-60-97 \% \text { according to gender in goal } 5 . \\
3-40 \% \text { representing climate change in goal } 13 \text {. }\end{array}$ \\
\hline [7] & $\begin{array}{l}\text { Access to clean cooking } \\
\text { fuels and technology }\end{array}$ & $\begin{array}{l}\text { Energy policy to target SDG } 7 \\
\text { 1-Ending poverty was excellent in SDG1 by } 96.3 \% \\
\text { 2-89.1\% combating climate action in SDG13 } \\
\text { 3-In SDG9, industry, innovation, and infrastructure with } 23.5 \% \\
4-34.9 \% \text { in SDG10 by reducing inequality. }\end{array}$ \\
\hline [8] & $\begin{array}{l}\text { Electrification and } \\
\text { electricity for cooking }\end{array}$ & $\begin{array}{l}\text { Access to electricity has potential empowerment for women and gender equality in goal } \\
5 .\end{array}$ \\
\hline [13] & Cooking Energy & $\begin{array}{l}\text { Accessing to modern energy as a key part of SDG } 7 \text { is enhancing } \\
\text { 1- No Poverty in goal } 1 . \\
\text { 2- Zero Hunger in goal } 2 . \\
\text { 3- Good Health and Well-being in goal } 3 . \\
\text { 4- Quality Education in goal } 4 . \\
\text { 5- Gender Equality in goal } 5 . \\
\text { 6- Decent Work and Economic Growth in goal } 5 . \\
\text { 7- Sustainable Energy in goal } 7 . \\
\text { 8- Climate Action in goal } 13 . \\
\text { 9- Life on Land in gaol } 15 .\end{array}$ \\
\hline \multicolumn{3}{|c|}{ Scenario 2: Energy Access } \\
\hline [3] & Energy access (SDG 7) & Energy access to target SDG 7 can improve gender equity SDG 5. \\
\hline [12] & Access to energy & $\begin{array}{l}\text { Improved electrification rates can encourage } \\
\text { 1-Economic growth in SDG8. } \\
\text { 2-Reduce food insecurity in SDG } 2 . \\
\text { 3- Reduce gender inequality in SDG5. } \\
\text { 4-Alleviate poverty in SDG1. } \\
\text { 5-Promote industrialization in SDG } 9 . \\
\text { 6-Reduce the climate change in SDG13. }\end{array}$ \\
\hline [19] & Accessing to energy & $\begin{array}{l}\text { Ensure accessing to modern, affordable, sustainable, and reliable energy for everyone in } \\
\text { this world and interlinkage with sustainable development goal } 3 \text { on Health. }\end{array}$ \\
\hline [20] & Energy use & Energy poverty has a greater impact on women' opportunities. \\
\hline \multicolumn{3}{|c|}{ Scenario 3: Energy Efficiency } \\
\hline [1] & Energy Efficiency & $\begin{array}{l}\text { There relation between LEED } 2009 \text { Prerequisites and Credits EA Category in LEED and } \\
\text { SDGs is positive such as } \\
\text { 1-Affordable and Clean Energy in goal } 7 . \\
\text { 2- Decent Work and Economic Growth in goal } 8 . \\
\text { 3-Industry, Innovation and Infrastructure in goal } 9 . \\
\text { 4-Responsible Consumption and Production in goal } 12 . \\
\text { 5-Climate Action in goal 13. }\end{array}$ \\
\hline [21] & Energy Efficiency & $\begin{array}{l}\text { The contribution of LEED BD+C New Construction (v2.2) Energy atmosphere (EA) and } \\
\text { SDGs: } \\
\text { 1- Affordable and Clean Energy in goal } 7 \\
\text { 2- Decent Work and Economic Growth in goal } 8 . \\
\text { 3-Industry, Innovation and Infrastructure in goal } 9 . \\
\text { 4-Responsible Consumption and Production in goal } 12 . \\
\text { 5- Climate Action }\end{array}$ \\
\hline
\end{tabular}


6-Terrestrial ecosystem, manage forests, combat desertification, land degrading, and halt biodiversity in goal 15 .

\begin{tabular}{|c|c|c|}
\hline \multicolumn{3}{|c|}{ Scenario 4: Renewable Energy } \\
\hline [9] & Renewable Electricity & $\begin{array}{l}\text { The strong synergies effect between the prices of renewable electricity and sustainable } \\
\text { development goals such as } \\
\text { 1-Affordable and clean energy) in } 7 \text { goal. } \\
\text { 2-Decent work and economic growth in goal } 8 . \\
\text { 3-Industry, innovation and infrastructure in goal } 9 . \\
\text { 4-Responsible production and consumption in goal } 12 \text {. } \\
\text { 5-Climate action in goal } 13 \text {. }\end{array}$ \\
\hline [10] & $\begin{array}{l}\text { Renewable Energy Sources } \\
\text { (RES) }\end{array}$ & $\begin{array}{l}\text { Energy is associated with many of SDGs, for example, decent jobs in SDG 8, income SDG } \\
\text { 8, pollution SDG } 13 \text { and ecosystems in SDG 15, how the national energy policies will } \\
\text { contribute to sustainable development goals. }\end{array}$ \\
\hline [11] & Bioeconomic strategy & $\begin{array}{l}\text { There is a positive collection between the bioeconomy and } \\
\text { 1-Clean energies in sustainable development goal } 7 . \\
\text { 2-Recycling in sustainable development goal } 11 . \\
\text { 3-Ecosystem preservation in sustainable development goal } 15 \text {. }\end{array}$ \\
\hline
\end{tabular}

And negative correlations between

1-Agrobiodiversity in sustainable development goal 2.

2- Domestic material consumption of biomass in sustainable development goal 8 and sustainable development goal 12.

3-Agriculture and industrial developments in sustainable development goal 2 and sustainable development goal 9.

\begin{tabular}{|c|c|c|}
\hline [14] & Renewable Energy & $\begin{array}{l}\text { Exam the electricity and the use of energy heat moving toward sustainable strategies to } \\
\text { mitigate carbon dioxide emissions by modelling with sustainable development goal } 7,8 \text {, } \\
9 \text { and } 13 \text {. }\end{array}$ \\
\hline [15] & Renewable energy (Biofuel) & $\begin{array}{l}\text { The biofuels have contributed to achieving sustainable development goal } 13 \text { and they } \\
\text { caused a negative impact on other sustainable development goals. }\end{array}$ \\
\hline [17] & $\begin{array}{l}\text { Renewable Energy } \quad(P V \\
\text { solar })\end{array}$ & $\begin{array}{l}\text { To end poverty in SDG1, to promote economic growth in SDG } 8 \text {, To protect the } \\
\text { environment in SDG 12, climate change in SDG13, health and quality of life in SDG } 3 \text {. }\end{array}$ \\
\hline [22] & Bioenergy crops & $\begin{array}{l}\text { Food security in SDG2, reliable, sustainable and modern energy in SDG 7, and combat } \\
\text { climate change in SDG } 13 \text {. }\end{array}$ \\
\hline \multicolumn{3}{|c|}{ Scenario 5: Energy Services } \\
\hline [4] & Energy services. & $\begin{array}{l}\text { Rural electrification can improve water in SDG6 energy within sdg7, and food security } \\
\text { in SDG2, healthcare in SDG3, and education within SDG } 4 \text {. }\end{array}$ \\
\hline [16] & Justice/energy & $\begin{array}{l}\text { Mitigating rising energy demand in built environment design can contribute to SDG } 7 \\
\text { and goals. }\end{array}$ \\
\hline \multicolumn{3}{|c|}{ Scenario 6: Miscellaneous Energies } \\
\hline [2] & Offshore Wind Technology & The SDG 7, SDG9, SDG12, SDG 13, SDG14 goes hand in hand with Offshore wind energy. \\
\hline [23] & Energy & $\begin{array}{l}\text { Proposing a unique technique to identify the most representative sustainable } \\
\text { development goals indicator for measurement using sustainable development goal } 7\end{array}$ \\
\hline [24] & Energy Consumption & $\begin{array}{l}\text { The goal } 13 \text { could eliminate the climate change mitigation by a reducing in } \\
\text { anthropogenic emissions, goal } 12 \text { for ensuring sustainable consumption patterns, and the } \\
\text { goal } 8 \text { for ensuring sustainable economic growth by accounting energy consumption and } \\
\text { population. }\end{array}$ \\
\hline [25] & Energy Strategies & $\begin{array}{l}\text { SDG1: poverty reduction, SDG6: the water-related ecosystems protection and } \\
\text { restoration, decoupling of economic growth in SDG8, sustainable and resilient } \\
\text { infrastructure and industrialization in SDG9, sustainable transport, urban planning and } \\
\text { participation, reducing the environmental impact in SDG11, efficient use and sustainable } \\
\text { management of natural resources in goal 12, integrating into national policies, strategies } \\
\text { and planning the climate change measures in goal13, and sustainable use of different } \\
\text { ecosystems in SDG } 15 \text {. }\end{array}$ \\
\hline [26] & Energy Project & Sustainable development goals. \\
\hline
\end{tabular}

\section{Discussion}

The primary purpose of the systematic review is to update the latest research classifications of the energy to different energy scenarios for example: (modern energy, energy 
access, renewable energy, energy efficiency, energy services and other energies) towards SDG 7 and interlinking them with other SDGs for easy comprehension and subsequent utilization as regarding further research endeavours. The outcome of this review highlighted the significant trends in this field of energy studies which was obtained after reading the final set of the related articles that yielded the proposed taxonomy. This section has discussed the papers from five different perspectives, which are opportunities, constraints, recommendations, limitations, and new directions for future work in the Figure 7 . The importance and significance of these perspectives are mapping this review to the future researchers and authors by reporting the constrains that the previous researchers have found in this area. Besides, the opportunities have provided stimulation to potential researchers to conduct their research on this novel field of energy related topics. Lastly, recommendations and new directions are discussed for future researchers, authors, and contributors for mitigating the challenges the previous scholars faced during their various research undertakings as well as acting religiously in exploring more in this field of study. The authors have vividly defined the limitations of the previous researchers in a way to guides all interested and it can be transformed for future peers who will purpose a similar type of studies to transform such challenges into their future studies. Therefore, future authors and researchers will expand the previous research for upgrade and improvement in this domain.

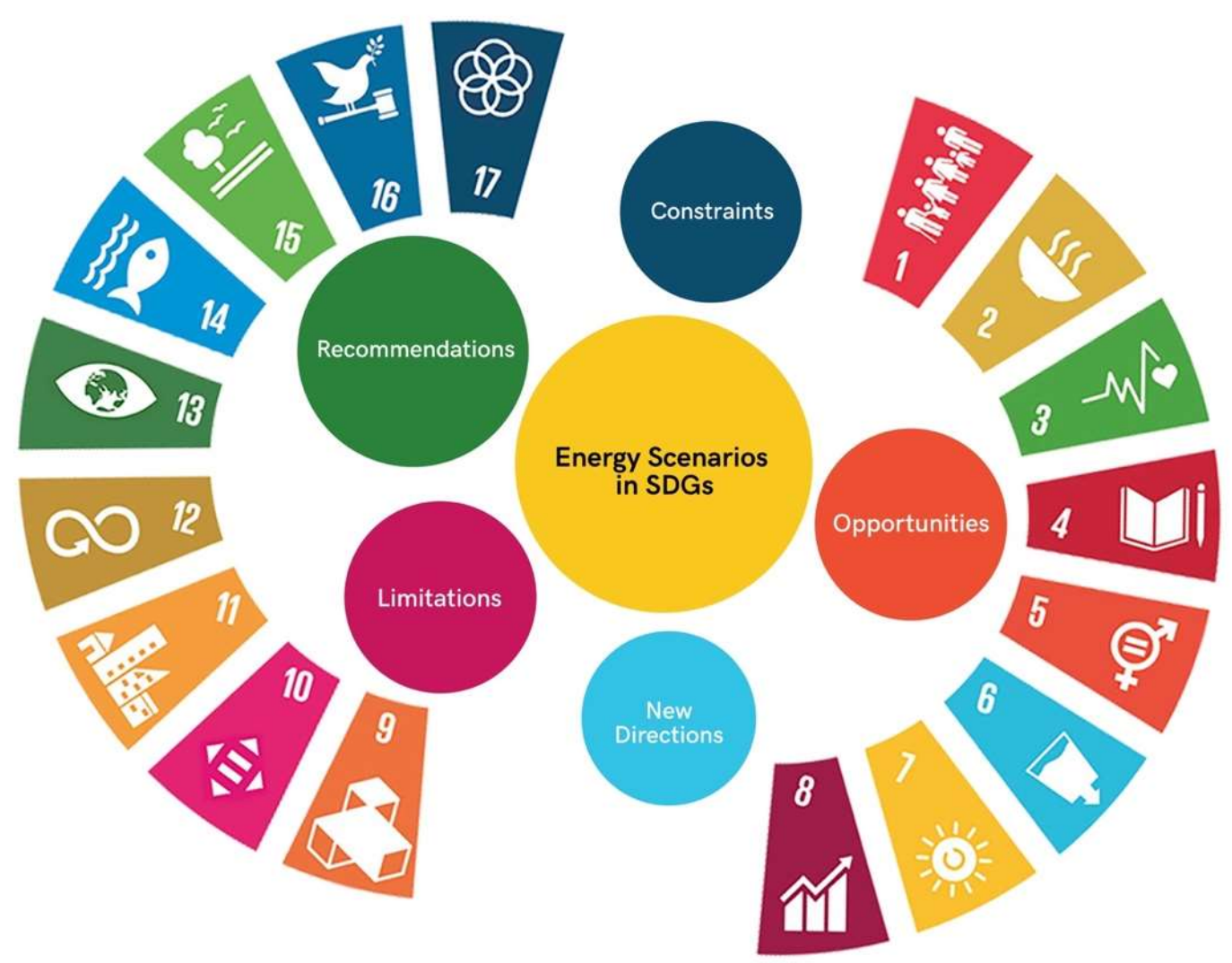

Figure 7. Opportunities, Constraints, Recommendations, Limitations, New directions for new research.

\subsection{Modern Energy Scenario:}

Accessing the modern energy by 2030 to all will achieve the main aim of sustainable development goal 7 and fulfil the other SDGs. Hence, there are some significant factors such as opportunities: achieving better health special for girls and women, creating income and improving livelihood, children's education, poverty reduction for women in rural area, communication technologies, and economic growth. Moreover, the constraints that found in Modern energy studies across different domains were descried, as presented in 
the previous taxonomy in Figure 3. These constraints are relying on using biomass, interrelated socio-economic and cultural factors, air pollution from cooking with firewood. Recommendations, limitations and new direction for future work were potentially affecting the modern energy scenario and by analysing these factors as follows in the table 8, will provide an insight into understanding this scenario.

Table 8. Scenario 1: Modern energy towards SDG 7 and interlink with other SDGs.

\begin{tabular}{l|c}
\hline Opportunities & Reference \\
\hline $\begin{array}{l}\text {-Analysing the socio-economic and socio-technical challenges for adopting and improving cooking } \\
\text { energy technologies, appliances power, and lighting that suitable for local demands and conditions. }\end{array}$ & {$[5]$} \\
\hline $\begin{array}{l}\text {-A comprehensive analysis and comparisons of various co-benefits of clean cooking solutions in rural } \\
\text { and urban settings with sustainable development goal 3- health, sustainable development goal 5- }\end{array}$ & {$[6]$} \\
$\begin{array}{l}\text { gender, and sustainable development goal 13 - climate change via a cost-benefit analysis method by } \\
\text { utilising a comprehensive approach. }\end{array}$ & \\
\hline
\end{tabular}

-Assessing and examining the interactions of energy policy in supporting and achieving the goal $7^{\prime \prime}$ targets towards universal accessing energy, increasing the shar of renewable energy sources, and improving of the energy efficiency.

-Examining that how accessing the electricity can contribute to the women' empowerment via gender and energy.

-Exploring the alternative approaches and programmes of modern energy cooking for addressing cooking energy challenges in the UK.

\begin{tabular}{l|c}
\hline Constrains & Reference \\
\hline $\begin{array}{l}\text {-Accessing to electricity, modern cooking energy and depending on biomass energy will be very } \\
\text { challenging until } 2030 \text { according to the delivery of quality of life, social services, and economic } \\
\text { development. }\end{array}$ & {$[5]$} \\
\hline $\begin{array}{l}\text { - Lacking in accessing to clean cooking solutions in rural areas and utilising the traditional use of } \\
\text { biomass. }\end{array}$ & {$[6]$} \\
\hline $\begin{array}{l}\text {-Difficulty in accessing to the clean cooking technology for everyone in the least developed regions in } \\
\text { Indonesia by } 2030 \text { and the current policy scenario is not sufficient for reducing in using solid biomass } \\
\text { and allowing enough progress in achieving the renewable energy target. }\end{array}$ & {$[7]$} \\
\hline $\begin{array}{l}\text {-In rural areas, lacking in affordability of electricity in the larger context are challenging such as } \\
\text { changing gender norms, empowerment of women, and gender inequalities. }\end{array}$ & {$[8]$} \\
\hline $\begin{array}{l}\text { - For cooking, the biomass' constraints are well known, there is no equality between the improving of } \\
\text { cookstoves and the population growth, and advances in accessing modern energy not yet on tracking } \\
\text { to reach the international community. }\end{array}$ & {$[13]$} \\
\hline Limitations & Reference \\
\hline
\end{tabular}

\begin{tabular}{l|c}
\hline Limitations & Reference \\
\hline $\begin{array}{l}\text {-The data were not confirmed because of difficulty in the study' time frame for the whole reference } \\
\text { period and a limitation in sample size. }\end{array}$ & {$[6]$} \\
\hline Recommendations & Reference \\
\hline
\end{tabular}

-Further studies are recommended on specific policy direction, income generation, system [5] integration, and forwarding clear.

-The improving of the policy should focus on easing the sociocultural challenges and the socioeconomic incentives to create income and improve livelihood for households.

\begin{tabular}{l|c|}
\hline $\begin{array}{l}\text {-Further studies should use non-renewable biomass fraction (FNRB) which is determined by using } \\
\text { methods such as wisdom model. }\end{array}$ & {$[6]$} \\
\hline $\begin{array}{l}\text {-Upscaling of Renewable energy, removing subsidies for fossil fuels, and improving energy efficiency } \\
\text { are needed to keep on tracking with the } 2{ }^{\circ} \mathrm{C} \text { pathway of sustainable development goal } 13 .\end{array}$ & {$[7]$} \\
-For Indonesia in 2025 especially for cooking, revising the universal electricity access target and zero \\
traditional use of biomass may be needed. \\
$\begin{array}{l}\text {-Executing the improving cookstoves (ICS) program in line with Liquefied Petroleum Gas and Solar } \\
\text { Systems. Also executing rural energy programs such as (Rural Electrification and Clean Cooking) } \\
\text { should be supported and funded under allocated budget. }\end{array}$
\end{tabular}




\subsection{Energy Access Scenario:}

Accessing energy such as electricity is an essential for economic development to end poverty and supporting sustainable urbanisation and industrialisation. In addition, it is important at the health-facility level to design effective policies for improving the healthcare quality for the population, improving gender equity, having clean cooking solutions, ending poverty, promoting industrialisation, and reducing the climate change. However, lacking it can give poor health systems, facing significant illness and people can die from indoor air pollution by using firewood and charcoal for cooking, lacking in educational activities because women are collecting biomass per day for cooking. The literature review in this scenario has numerous recommendations which represent different authors' views including for healthcare facilities equipment with low energy is needed, sharing data and financial resources, providing clean cooking solutions and using sustainable technologies. However, the opportunities, constrains limitations, recommendation and new directions for energy access has been elaborated more in the Table 9. below.

Table 9. Scenario 2: Energy Access towards SDG 7 and interlink with other SDGs.

\begin{tabular}{|c|c|}
\hline Opportunities & Reference \\
\hline $\begin{array}{l}\text {-To design an effective policy for improving the quality of healthcare, systematic documentation in accessing energy } \\
\text { is important. } \\
\text {-Accessing electricity is crucial for healthcare from basic to ultimate services. }\end{array}$ & [19] \\
\hline -Increasing in accessing electricity can benefit women. & [3] \\
\hline $\begin{array}{l}\text {-To investigate and explore the strategies, policies, and innovations that might help in accessing energy before } 2030 \\
\text { in sub-Saharan Africa. }\end{array}$ & [12] \\
\hline -Interest and awareness to the ways in that drive gender equality in achieving sustainable energy solutions. & [20] \\
\hline Constrains & Reference \\
\hline $\begin{array}{l}\text {-Lacking in accessing modern energy and energy poverty have left almost } 1 \text { billion people without access to sufficient } \\
\text { healthcare facilities. }\end{array}$ & [19] \\
\hline $\begin{array}{l}\text {-Few have tested and less attention in the linking between the accessing energy in goal } 7 \text { and the gender equality in } \\
\text { goal } 5 \text { especially for a household. }\end{array}$ & [3] \\
\hline $\begin{array}{l}\text {-Africa still cannot have energy access achieve by } 2030 \text { because corruption, economic growth and access to finance. } \\
\text { - There are knowledge gaps between initiatives and programmes of SDGs and access to energy to foster towards } \\
\text { universal electrification. }\end{array}$ & {$[12]$} \\
\hline $\begin{array}{l}\text {-In the worldwide, around } 1.06 \text { billion people don't have electricity and around } 3.04 \text { billion people don't reach the } \\
\text { clean cooking solutions. In developing countries, women are affected by energy poverty more than men. }\end{array}$ & {$[20]$} \\
\hline Recommendations & Reference \\
\hline $\begin{array}{l}\text {-For improving access to electricity in healthcare facilities, Innovative technology and equipment with low power are } \\
\text { needed such as LED lighting, 'Solar Suitcases', refrigerator, solar-powered vaccine, digital X-rays and new low-power } \\
\text { LED lighting. } \\
\text {-In healthcare facilities, improving data on the access of the electricity, data collection' quality and frequency, an } \\
\text { extension of the geographic coverage, standardised the tracking systems, and the energy access' systematic } \\
\text { documentation. }\end{array}$ & [19] \\
\hline $\begin{array}{l}\text {-More empirical analyses to identify and test the factors that link between SDGs together. And more studies with the } \\
\text { local social context for assessing the linkage between targets of the SDG. }\end{array}$ & [3] \\
\hline $\begin{array}{l}\text { - The financial resources should be shared and distributed for improving energy access by } 2030 \text {. } \\
\text { - Africa needs more projects for enhancing the electrification of rural areas and linking universal energy to agriculture } \\
\text { development. } \\
\text { - In rural areas, the energy transition is needed by using RE technologies and improve it. }\end{array}$ & [12] \\
\hline $\begin{array}{l}\text {-Humanitarian agencies should be converted from (Diesel-Generated Power to Renewable-Powered Electricity) and } \\
\text { for residents, providing clean cooking solutions than collecting firewood. } \\
\text {-Expand the decentralisation of the energy services based on gender gaps } \\
\text {-To take the benefits from the massive reductions in technology costs, the benefits of the integration between the } \\
\text { technologies, addressing the cost barriers, and new business models. } \\
\text {-Expand mobile money in less-developed countries where there is a lack of services and consider the household } \\
\text { female' needs. } \\
\text {-For women and men who live in rural areas, the policymakers need to circulate the tenure and payment barriers. }\end{array}$ & [20] \\
\hline
\end{tabular}


-Accessing the energy, policymakers need to support the women who owned small and medium-sized enterprise and other aspects of their wellbeing. - Replacing the diesel generators to sustainable technologies with DRE systems for reducing fuel and operation costs.

New Directions

Reference

-Developing policies effectively by using the local international resources sufficiently and policies to facilitate the fast [12] progress towards energy access.

\subsection{Energy Efficiency Scenario:}

There are many opportunities have been found in in achieving energy efficiency scenario. For example, in buildings which, the energy efficiency is considered a major driver for innovation and technology, can reduce the building's energy use' environmental impacts, providing sustainability for buildings, creating jobs in manufacturing; construction; operations; design; and maintenance, maximising the contribution towards achieving UN SDGs. However, there were many constraints for achieving the energy efficiency such as Lacking in the accessibility of electricity, renewable energy is high in cost. The researchers have recommended having more studies, using Nano-grid solutions, removing the support from non-renewable sources. The limitations and the new directions for future work to the authors and researchers are more in details as shown in Table 10. Below.

Table 10. Scenario 3: Energy efficiency towards SDG 7 and interlink with other SDGs.

\begin{tabular}{l|c}
\hline Opportunities & Reference \\
\hline $\begin{array}{l}\text { - In Jordan, investigating How the Energy Efficiency in green buildings is certified by LEED 2009 rating system } \\
\text { for achieving UN-SDGs }\end{array}$ & [1] \\
\hline $\begin{array}{l}\text {-Develop a method for determining the Energy Efficiency with Water in green buildings rating systems for } \\
\text { achieving the UN-SDGs. }\end{array}$ & [21] \\
\hline $\begin{array}{l}\text { Constrains } \\
\text { - Investigation of the contributions of energy efficiency in LEED certification of green buildings in Jordan to } \\
\text { achieve the SDGs have not been done before. }\end{array}$ & [1] \\
\hline $\begin{array}{l}\text {-A method to determine the contributions of energy efficiency and water for achieving the UN-SDGs has not } \\
\text { been developed. }\end{array}$ & [21] \\
\hline $\begin{array}{l}\text { Recommendations } \\
\text { - The stakeholders such as designers, developers, and governments should be enlightened with the benefits of } \\
\text { investing in energy efficiency in green buildings to achieve UN-Sustainable Development Goals }\end{array}$ & [1] \\
\hline $\begin{array}{l}\text { - The different decisions according to constraints of the water and energy need to be formulated and organized } \\
\text { within an integrated response. }\end{array}$ & [21] \\
\hline
\end{tabular}

\subsection{Renewable Energy Scenario:}

This section describes the main constraints found in renewable energy scenario studies across different databases. The constraints are lacking in the accessibility of electricity, tools, studies, highly carbon dioxide emission, and other. In additions, for systematic renewable energy scenario, different significances and opportunities show researchers' concern in this area. These motivations are summarized and grouped in the following Table 11. such as introducing a method for identifying the most suitable renewable energy systems, examining the energy conservation strategies, using the bioenergy crop, implementing the off-grid houses and so on. However, there were only two limitations studies within the renewable energy studies one is lacking in selecting best energy strategy and harmony between the researchers. Moreover, in this section, the literature review summarises previous recommendations and future directions for researchers. These recommendations were classified depend on their relevance, as shown in Table 11. 
Table11. Scenario 4: Renewable Energy towards SDG 7 and interlink with other SDGs.

\begin{tabular}{|c|c|}
\hline Opportunities & Reference \\
\hline $\begin{array}{l}\text {-To reduce fossil fuels' dependency and increase the SD by third-generation biofuels, the biofuels are } \\
\text { considered as promising alternative solutions. } \\
\text {-Exploring the relation between biofuels and sustainable Development goals to present the } \\
\text { challenges, motivations, and current developments. }\end{array}$ & [15] \\
\hline $\begin{array}{l}\text {-For increasing the electricity access and for implementing the off-grid houses by using renewable } \\
\text { energies such as sea-salt battery, glycerol fuel cell, and solar PV. }\end{array}$ & [17] \\
\hline $\begin{array}{l}\text { - Introducing a method such as the numerical decision support to identify the most suitable } \\
\text { renewable energy systems. }\end{array}$ & [10] \\
\hline - Examining the energy conservation strategies and her substitution that can mitigate CO2 emissions. & [14] \\
\hline -Analysing synergies and tensions between the bioeconomic strategy and SDGs targets. & [11] \\
\hline $\begin{array}{l}\text {-For the EU countries, examining the effect of renewable electricity on SDGs through electricity prices. } \\
\text {-Examining the impact price of (RE) on the energy system and other sustainable developments goals } \\
\text { still not investigated. }\end{array}$ & [9] \\
\hline $\begin{array}{l}\text { - Using the bioenergy crop can improve incomes for farm, emissions increase the soil carbon, reduce } \\
\text { greenhouse gas stock, for food production, make the marginal areas suitable, and emissions increase } \\
\text { the soil carbon. }\end{array}$ & [22] \\
\hline Constrains & Reference \\
\hline $\begin{array}{l}\text {-To use energy from renewable energy becomes crucial nowadays. } \\
\text {-Lacking studies about the impact of the biofuels on sustainable development goals. }\end{array}$ & {$[15]$} \\
\hline $\begin{array}{l}\text { - Lacking in the accessibility of electricity would not be capable to achieve the SDG } 7 \text { target in the } \\
\text { region such as Africa and South Asia. }\end{array}$ & {$[17]$} \\
\hline $\begin{array}{l}\text {-For policy- makers, lacking tools for policymakers to direct them with their local policies in } \\
\text { conjunction with SDGs. } \\
\text {-The selection of RE source according to the decision-makers to SDGs can be a challenge. }\end{array}$ & [10] \\
\hline $\begin{array}{l}\text {-The challenges in MENA regions such as carbon dioxide emission and high energy intensity could } \\
\text { not achieve SDGs } 7,8 \text {, and } 13 \text {. }\end{array}$ & {$[14]$} \\
\hline $\begin{array}{l}\text {-The first bio-economy strategy (EU) has not criticised for its unbalanced contribution towards SD } \\
\text { market, technology and the biomass production' multi-functionality. }\end{array}$ & [11] \\
\hline $\begin{array}{l}\text { - In } 2016 \text { in the EU, the energy consumption has increased to } 7 \% \text { mean that has raised to } 8.5 \% \text { over } \\
\text { the } 2004 \text { value. }\end{array}$ & [9] \\
\hline -Under specific climatic conditions, there are not always sustainable economic. & [22] \\
\hline Limitations & Reference \\
\hline -In the literature of biofuels sustainability, lacking harmony between the researchers. & [15] \\
\hline -Limitation in the selection of best energy strategy at the national level for sustainability context. & {$[17]$} \\
\hline Recommendations & Reference \\
\hline $\begin{array}{l}\text {-For achieving sustainable developments goals targets, individuals, stakeholders, governments, and } \\
\text { civil society should be involved. } \\
\text {-It can be used as a Nano-grid solution in rural areas. }\end{array}$ & [17] \\
\hline $\begin{array}{l}\text { - For the same problem, more research is needed to compare the proposed method with other MCDM } \\
\text { methods }\end{array}$ & {$[10]$} \\
\hline $\begin{array}{l}\text { - Removing the support from non-renewable sources, saving the energy in non-productive sectors of } \\
\text { the MENA region, replacing non-renewable energy with cleaner and affordable energy and } \\
\text { implementing the taxes to } \mathrm{CO} 2 \text { emissions in electricity sectors. } \\
\text { - The energy technology innovations should be improved by enhancing the power plant retrofitting } \\
\text { to improve efficiency and reduce } \mathrm{CO} 2 \text { emissions. }\end{array}$ & [14] \\
\hline $\begin{array}{l}\text {-Replicating the methodology at other national and regional levels with different socioeconomic and } \\
\text { environmental contexts. } \\
\text {-Future updates are possible for assessing the synergies and trade-offs. }\end{array}$ & [11] \\
\hline $\begin{array}{l}\text {-The policymakers should be more active for achieving sustainable development goals targets by } \\
2030\end{array}$ & [9] \\
\hline $\begin{array}{l}\text {-The measurements are needed for tackling the climate change, cropping production and sustaining } \\
\text { the local farming communities. }\end{array}$ & [22] \\
\hline New Directions & Reference \\
\hline
\end{tabular}




\begin{tabular}{l|c|}
\hline $\begin{array}{l}\text { - More research about the improvement and contribution of biofuels toward achieving the SDGs are } \\
\text { needed. }\end{array}$ & {$[15]$} \\
\hline $\begin{array}{l}\text {-To Secure electricity access, by adopting two strategies such as in urban and suburban areas, } \\
\text { extending the grid base electrification and in rural areas, using off-grid electrification. }\end{array}$ & {$[17]$} \\
\hline $\begin{array}{l}\text {-For handling the RE sources selection with considering SDGs, MCDM methods are needed to be } \\
\text { implemented. }\end{array}$ & {$[10]$} \\
\hline - Deep understanding in the electricity sector and implementing strategies is needed. & {$[14]$} \\
\hline $\begin{array}{l}\text {-The trade-offs associated with the consumption of the Europeans to the biomass materials is much } \\
\text { needed than technical solutions. }\end{array}$ & {$[11]$} \\
\hline - Designing the policies can make harmony and intergradation between the various SDGs. & {$[9]$} \\
\hline
\end{tabular}

\subsection{Energy Services Scenario:}

People consume cultural energy services. The energy services can be classified to comfort, cleanliness, and convenience (3Cs), which lead the energy consumption culture into society. the cultural energy services affect the occupants' well-being. However, there are only two studies related energy service scenario from our databases. In this section the review focuses on reviewing the Opportunities such as investigation related to the factors affecting the energy service and investigation of electricity demand and supply for improving energy services, constraints such as health and environmental problems, lacking in infrastructure, paying for improving energy service is difficult, recommendations by using different approaches and systems with distributing the energy justice policies, limitation and new direction for future work which, are explained in more details in Table 12.

\begin{tabular}{|c|c|}
\hline Opportunities & Reference \\
\hline $\begin{array}{l}\text {-Understanding the drivers are necessary for improvising areas where the occupants are struggling } \\
\text { to benefit from the essential energy services. } \\
\text {-For SRH, the investigation on the socio-architectural influence on cultural energy services, which } \\
\text { can encourage the distributive justice. }\end{array}$ & [16] \\
\hline $\begin{array}{l}\text { - Investigating the demand for electricity and the supply by using off-grid small hydropower energy } \\
\text { a local level to be sustainable in a nexus approach for improving water, energy, and food security. }\end{array}$ & {$[4]$} \\
\hline Constrains & Reference \\
\hline $\begin{array}{l}\text { - In low-income areas, addressing the energy via provisioning of 3Cs to be critical energy, creating } \\
\text { health problems, environmental problems such as greenhouse gases and deforestation. }\end{array}$ & [16] \\
\hline $\begin{array}{l}\text {-The electrification rate has been slow because some challenges such as lacking in basic } \\
\text { infrastructure, institutional barriers, the gap between electricity supply and electricity demand, and } \\
\text { paying for energy services is difficult. }\end{array}$ & {$[4]$} \\
\hline Limitations & Reference \\
\hline $\begin{array}{l}\text {-The remain limitation of this study is generalisation of the bias-reduced empirical model. Across } \\
\text { the global south, heterogeneity in the poverty area rehabilitation contexts is high. }\end{array}$ & [16] \\
\hline Recommendations & Reference \\
\hline $\begin{array}{l}\text {-For slum households, distributing the energy justice policies should involve the needs of the socio- } \\
\text { architectural built environmental such as higher privacy gradients, open spaces, and better safety, } \\
\text { hygiene and sanitation. }\end{array}$ & [16] \\
\hline $\begin{array}{l}\text {-Using the mini-grid hydropower system in small-scale industry for increasing the economic } \\
\text { profitability. Using small rivers and suitable topography for developing rural electrification. Using } \\
\text { a bottom-up nexus approach for improving the economic conditions and environment by fewer } \\
\text { needs for artisanal gold mining. } \\
\text {-Strengthening the national framework by technical support, loan possibilities, and a simpler } \\
\text { approach is needed for supporting the small and independent power producers. }\end{array}$ & {$[4]$} \\
\hline New Directions & Reference \\
\hline habilitation Building lypologies for improving & [16] \\
\hline
\end{tabular}


-Creating the database of energy cultures across slum rehabilitation housing with various socioarchitectural contexts can drive the planners and policymakers to take decision making with evidence.

\subsection{Miscellaneous Energies Scenario:}

The last energy scenario is Miscellaneous meant to highlight the remaining opportunities, constraints, limitations, recommendations, new directions by previous researchers which, do not fall into previous scenarios for energy and does not connect with each other. They are presented in Table 13 as shown below.

Table 13. Scenario 6: Miscellaneous Energies towards SDG 7 and interlink with other SDGs.

\begin{tabular}{|c|c|}
\hline Opportunities & Reference \\
\hline $\begin{array}{l}\text {-The benefits of Offshore wind power are considered as the clean energy of the future, high } \\
\text { availability of the number of resources does not limit in the region and it doesn't emit the (GHG). } \\
\text {-Such wind farms have wind turbines, increasing the power installed at dramatic rate and } \\
\text { depths increasing-almost } 100 \mathrm{~m} \text { deep the leaving shallow waters. }\end{array}$ & [2] \\
\hline $\begin{array}{l}\text {-Proposing a unique technique to identify the most paradigmatic indicator set for sustainable } \\
\text { buildings measurement based on the sustainable developments goals by taking consideration of the } \\
\text { country' needs and preferences. }\end{array}$ & [23] \\
\hline $\begin{array}{l}\text {-Examining the relationship between economic growth, climate change especially (CO2 emissions), } \\
\text { energy consumption, and population. }\end{array}$ & {$[24]$} \\
\hline $\begin{array}{l}\text {-Introducing and discussing the ideas and basic principles of energy planning and integrated spatial } \\
\text { to achieve the energy transition and supporting further sustainable developments goals. }\end{array}$ & [25] \\
\hline $\begin{array}{l}\text {-Presenting the development and application of sustainable development goals-IAE for synergies } \\
\text { and trade-offs of the qualitative assessment target considering energy project. }\end{array}$ & [26] \\
\hline Constrains & Reference \\
\hline -There is not a deep reflection on the impact of the offshore wind on sustainable development goals. & [2] \\
\hline -There is no formal sustainable development goal indicator set. & {$[23]$} \\
\hline $\begin{array}{l}\text {-Addressing the challenges of sustainable development goals such as eradication of poverty, } \\
\text { hunger, clean water and sanitation, good health and wellbeing, gender equality, quality education, } \\
\text { climate change, clean energy industrial innovation, and sustainable consumption and production } \\
\text { among others. }\end{array}$ & [24] \\
\hline Non & [25] \\
\hline $\begin{array}{l}\text {-The assessments of global action towards sustainable developments goals are slow because } \\
\text { identifying the interlinkages is more complex and scattered and one of the barriers for achieving } \\
\text { sustainable developments goals is lacking in method for evaluating the energy projects across } \\
\text { various aspects of SD and lacking information in SDG impact assessment tool and mapping the } \\
\text { interactions between them. }\end{array}$ & [26] \\
\hline Limitations & Reference \\
\hline -Limitation in considering the measures, underlying factors, a policy that related to emissions. & [24] \\
\hline Recommendations & Reference \\
\hline $\begin{array}{l}\text {-Special attention for other sustainable development goals for ensuring that the offshore wind } \\
\text { power technology will contribute to achieving them effectively. } \\
\text {-The sustainable development goal should overcome the challenges of offshore wind so that the } \\
\text { world becomes bluer. }\end{array}$ & {$[2]$} \\
\hline $\begin{array}{l}\text {-For achieving mitigating the climate change and middle-income status by } 2030 \text {, then most of the } \\
\text { countries are requesting a sustainable economic growth and productivity via innovation and } \\
\text { creativity, decarbonization, advancement, technological, diversification, and adding value to raw } \\
\text { materials. } \\
\text {-To reduce the energy consumption impact on environmental pollution, it should be an improving } \\
\text { in energy efficiency and separating the use of energy from the economic growth. }\end{array}$ & [24] \\
\hline $\begin{array}{l}\text {-Accessing to sustainable, clean, affordable, modern, and reliable energy services should be for } \\
\text { everyone in this world. Sharing the renewable energy should be on a global scale. Improving the } \\
\text { energy-efficiency. Promoting investments in clean energy technology and investments in energy }\end{array}$ & [25] \\
\hline
\end{tabular}


infrastructure. In developing countries, modernizing the energy infrastructure for providing sustainable energy services.

-Establishing the links between food versus fuel and energy-efficient spatial structures support active mobility.

-Validating the SDGs-IAE Framework should be made by using additional cases.

- After preliminary analysis, conducting the quantitative exploration of specific synergies and tradeoffs.

\begin{tabular}{l|c}
\hline New Directions & Reference \\
\hline $\begin{array}{l}\text {-The aim of future studies to assess the policy measures and drivers on immediate driver-attributa- } \\
\text { ble emissions. }\end{array}$ & [24] \\
\hline
\end{tabular}

-Spatializing and temporalizing of the decision-making models results and integrating the policy-

making which including financial steering instruments such as subsidies and taxes, integrating spatial and energy planning, awareness to raise the general public, education and training for experts, and public investments are needed.

- For energy project sustainability assessments, improving the tool depend on new case studies, [26] additional expert knowledge, and feedback of the users to be considered as an established tool in the future.

- The SDGs-IAE Framework can be used for better understanding the interactions between energy projects and the sustainable development goals and for enhancing the dialogue among the sectors and governing bodies.

\section{Conclusions}

The number of researchers on energy scenarios for achieving sustainable development goal 7 and interlinkage with other SDGs to rise. However, these types of researchers need more investigations for a quite number of limitations that have not addressed yet. The energy scenarios towards achieving sustainable development goals are a hot and emerging topic that needs further research. The main aim of this paper is to conduct a systematic review and to do classification for energy scenarios and can target SDG7 and other SDGs. The selected papers were grouped into six groups based on the type of energies: energy access, modern energy, energy services, energy efficiency, renewable energy, and miscellaneous energies. The selected reviews and articles extensively analysed and investigated by highlighting the opportunities, constraints, recommendations, limitations, and new directions in this field according to energy towards achieving sustainable development goals. The recommendations need to be implemented by governments, policymakers, developers, stakeholders, designers, and civil society for implementing policy, using different methods, executing programs, using renewable energy technologies, implementing taxes to $\mathrm{CO} 2$ emissions, activation the policymakers towards agenda 2030. However, the new directions are recommendations gives guidance and a way to the future authors and to overcome the constraints and challenges that the current authors did not solve. With the targeting of solving those constraints by sharing renewable energy on a global scale, energy efficiency improvements, promoting investments in clean energy technology and investments in energy infrastructure, accessing affordable, reliable, sustainable, and modern energy can achieve and contribute towards sustainable development goals. This systematic review has summarised also the methodical aspects of selected reviews and articles based on publication per year, country of study' implementation, type of journal, and impact factor to providing a valuable reference for future researchers. Considering that, topics connect with emerging energy scenarios in the context of SDGs need to be updated.

Author Contributions: Saad Mekhilef: Validation, Investigation, Visualization, Supervision, Funding acquisition. Taufiq-Yap Y.H.: Visualization, Investigation. Fatma S. Hafez: Conceptualization, 
Methodology, Validation, Formal analysis, Investigation, Resources, Data Curation, Writing - Original Draft, Visualization, and Funding acquisition. Da'u Abba Umar: Resources, Writing-Reviewing and Editing.

Funding: This research has not received any external funding.

Acknowledgements: The authors have profound gratitude to University Malaysia for their motivation to conduct this review. Moreover, the authors are also gratified for unanimous reviewers for their valuable suggestions and comments to improve the manuscript quality.

Conflicts of Interest: The authors have declared no conflict of interest. Also, the funders had no role in designing of this review, data collection, analyses the selected papers, interpretation of data; in writing the manuscript, and decision to publish the results.

\section{References}

1. Alawneh, R.; Ghazali, F.; Ali, H.; Asif, M. A new index for assessing the contribution of energy efficiency in LEED 2009 certified green buildings to achieving UN sustainable development goals in Jordan. Int. J. Green Energy 2019, 16,490-499.

2. Frades, J. L.; Barba, J. G.; Negro, V.; Martín-antón, M.; Soriano, J. Blue Economy: Compatibility between the Increasing Offshore Wind Technology and the Achievement of the SDG. J. Coast. Res. 2020, 95,1490-1495.

3. Rosenberg, M.; Armanios, D. E.; Jaramillo, P. Evidence of gender inequality in energy use from a mixed-methods study in India. Nat. Sustain. 2020, 3,110-118.

4. Uamusse, M. M.; Tussupova, K.; Persson, K. M.; Berndtsson, R. Mini-Grid Hydropower for Rural Electrification in Mozambique: Meeting Local Needs with Supply in a Nexus Approach. Water 2019, 11,305.

5. Tucho, G. T.; Kumsa, D. M. Challenges of Achieving Sustainable Development Goal 7 From the Perspectives of Access to Modern Cooking Energy in Developing Countries. Front. Energy Res. 2020, 8,564104.

6. Mazorra, J.; Sánchez-jacob, E.; De, C.; Fernández, L.; Lumbreras, J. Science of the Total Environment A comprehensive analysis of cooking solutions co-benefits at household level: Healthy lives and well-being, gender and climate change. Sci. Total Environ. 2020, 707,135968.

7. Santika, W. G.; Urmee, T.; Simsek, Y.; Bahri, P. A.; Anisuzzaman, M. Energy for Sustainable Development An assessment of energy policy impacts on achieving Sustainable Development Goal 7 in Indonesia. Energy Sustain. Dev. 2020, 59,33-48.

8. Kim, E.; Standal, K. Empowered by electricity? The political economy of gender and energy in rural Naryn gender and energy in rural Naryn. Gend. Technol. Dev. 2019, 23,1-18.

9. Bali, R.; Karimu, A. Renewable electricity and sustainable development goals in the EU. World Dev. 2020, 125,104693.

10. Buyukozkan, G.; Karabulut, Y.; Mukul, E. A novel renewable energy selection model for United Nations' sustainable development goals. Energy 2018, 165,290-302.

11. Commission, E.; Group, R. P. Friends or foes? A compatibility assessment of bioeconomy-related Sustainable Development Goals for European policy coherence. J. Clean. Prod. 2020, 254,119832.

12. Chirambo, D. Towards the achievement of SDG 7 in sub-Saharan Africa: Creating synergies between Power Africa, Sustainable Energy for all and climate fi nance in-order to achieve universal energy access before 2030. Renew. Sustain. Energy Rev. 2018, 94,600-608.

13. Batchelor, S.; Brown, E.; Scott, N.; Leary, J. Two Birds, One Stone - Reframing Cooking Energy Policies in Africa and Asia. Energies 2019, 12,1-18.

14. Lin, B.; Abudu, H. Can energy conservation and substitution mitigate CO2 emissions in electricity generation? Evidence from Middle East and North Africa. J. Environ. Manage. 2020, 275,111222.

15. Torres, M.; Janaína, N.; Luana, M.; Basso, G. Biofuels and their connections with the sustainable development goals: a bibliometric and systematic review. Environ. Dev. Sustain. 2020, 1-18.

16. Debnath, R.; Monteiro, G.; Simoes, F.; Bardhan, R.; Leder, S. M.; Lamberts, R.; Sunikka-blank, M. Energy Justice in Slum Rehabilitation Housing: An Empirical Exploration of Built Environment Effects on Socio-Cultural Energy Demand. Sustainability 2020, 12,3027.

17. Pulido, D. F. Q.; Kortenaar, M. V. Ten; Hurink, J. L.; Smit, G. J. M. energies The Role of Off-Grid Houses in the Energy Transition with a Case Study in the Netherlands. Energies 2019, 12,2033.

18. Nazir, S.; Nawaz Khan, M.; Anwar, S.; Adnan, A.; Asadi, S.; Shahzad, S.; Ali, S. Big Data Visualization in Cardiology - A Systematic Review and Future Directions. IEEE Access 2019, 7,115945-115958.

19. Ouedraogo, N. S.; Schimanski, C. Energy poverty in healthcare facilities: a "silent barrier" to improved healthcare in sub Saharan Africa. J. Public Health Policy 2018, 39,358-371.

20. Maestre, M.; Pearl-martinez, R. Gender and Energy: opportunities for all. Editors Ana Pueyo and. IDS Bull. $2020,51$.

21. Alawneh, R.; Mohamed Ghazali, F. E.; Ali, H.; Asif, M. Assessing the contribution of water and energy efficiency in green buildings to achieve United Nations Sustainable Development Goals in Jordan. Build. Environ. 2018, 146,119-132.

22. Bonfante, A.; Impagliazzo, A.; Fiorentino, N.; Langella, G.; Mori, M.; Fagnano, M. Science of the Total Environment Supporting local farming communities and crop production resilience to climate change through giant reed (Arundo Donax L.) cultivation: An Italian case study. Sci. Total Environ. 2017, 602,603-613.

23. Khalid, A. M.; Sharma, S.; Dubey, A. K. Developing an indicator set for measuring sustainable development in India. Nat. Resour. Forum 2018, 42,185-200. 
24. Sarkodie, S. A.; Ackom, E.; Bekun, F. V.; Owusu, P. A. Energy - Climate - Economy - Population Nexus: An Empirical Analysis in Kenya, Senegal, and Eswatini. Sustainability 2020, 12,6202.

25. Stoeglehner, G. Integrated spatial and energy planning: a means to reach sustainable development goals. Evol. Institutional Econ. Rev. 2020, 17,473-486.

26. Castor, J.; Bacha, K.; Nerini, F. F. Energy Research \& Social Science SDGs in action: A novel framework for assessing energy projects against the sustainable development goals. Energy Res. Soc. Sci. 2020, 68,101556. 